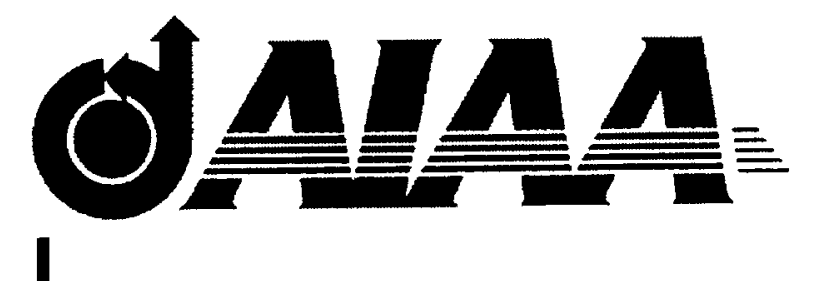

AIAA 2000-3242

\title{
Preliminary Design Optimization For A Supersonic Turbine For Rocket Propulsion
}

Nilay Papila ${ }^{(1)}$, Wei Shyy ${ }^{(1)}$. Lisa Griffin ${ }^{(2)}$,

Frank Huber ${ }^{(3)}$ and Ken Tran ${ }^{(1)}$

University of Florida, Gainesville. FL

${ }^{2)}$ NASA Marshall Flight Center. Huntsville. AL

$\because$ Riverbend Design Services. Palm Beach Gardens. FL

"Boeing - Rocketdyne Division. Canoga Park, CA

\section{6th AIAA/ASME/SAE/ASEE Joint Propulsion Conference and Exhibit 16-19 July 2000 / Huntsville. Alabama}




\title{
PRELIMINARY DESIGN OPTIMIZATION FOR A SUPERSONIC TURBINE FOR ROCKET PROPULSION
}

\author{
Nilay Papila*, Wei Shyy", Lisa Griffin ${ }^{\star}$, Frank Huber ${ }^{\ddagger}$ and Ken Tran ${ }^{\S}$ \\ - Department of Aerospace Engineering, Mechanics \& Engineering Science \\ University of Florida, Gainesville, FL \\ 'NASA Marshall Flight Center, Huntsville, AL \\ -Riverbend Design Services, Palm Beach Gardens. FL \\ "Boeing - Rocketdyne Division. Canoga Park, CA
}

\begin{abstract}
In this study, we present a method for optimizing, at the preliminary design level, a supersonic turbine for rocket propulsion system application. Single-. (wo)- and threestage turbines are considered with the number of design variables increasing from of to 11 then to 15 . in accordance with the number of states. Due 10 its global nature and tlexibility in handling different types of information. the response surface methodology (RSM) is applied in the present study. A major goal of the present optimization effort is to balance the desire of maximizing derodynamic performance and minimizing weight. Tio ascertain required predictive capability of the RSM. a (wo-level domain refinement approach has been adopted. The accuracy of the predicted optimal design points based on this strategy is shown to he satistactory. Our investigation indicates that the efficiency rises quichly from single stage 10 2 stages but thit the increase is much less pronounced with 3 stages A I-tage turhine pertioms

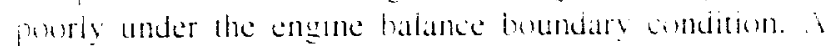
significant portion of tluid kinetic energy is lest at the turbine discharge of the 1 -stage design due to high stage pressure ratio and high-energy content. mostly hydrogen. if the working fluid. Regarding the iptumization echnique, issues related to the destgn of experimonts (DOE) hats also been investigated. It is demonstrated that the criteria for selecting the data hase exhibit significiant impact on the efficiency and etfectreness of the construction of the response surface.
\end{abstract}

\section{NOMENCLATURE}

$\begin{array}{ll}\text { ton } & \text { : Exit Blade Annulus Area } \\ \mathrm{C} & \text { : Chord } \\ \mathrm{D} & \text { : Diameter } \\ \mathrm{h} & \text { : Blade Height }\end{array}$

\begin{tabular}{|c|c|}
\hline$m$ & Mass flow \\
\hline$P$ & Pressure \\
\hline & Proportion of Variation \\
\hline & Root Mean Square \\
\hline RPM & Angular Speed \\
\hline & Standard Deviation \\
\hline & Standard Error \\
\hline & Stage Reaction \\
\hline$T_{n}$ & Input Temperature \\
\hline$\because$ & Pitch Speed \\
\hline & Weight \\
\hline$\therefore$ & Work Fraction \\
\hline Ipay & Payload Increment \\
\hline & Efficiency \\
\hline
\end{tabular}

\section{INTRODUCTION}

supersonic turbine technokegles wie being detively investigated in the rocket propulsion community. Optimizing a multistage turbine is a labor-intensive task and it is desirable to develop efficient and effective echniques (o undertake this lask. In general, two rypes of sptimization are needed, namely.

Preliminary design. in which amplified models employing loss correlations gleaned from experimental database and one-dimensional gasdynamic and thermodynamic considerations, and

2. Detailed shape design of the turbine blades, in which three dimensional computational fluid dynamics and detaled experimental information is employed.

In this study, we present an approach based on the response surface methodology' (RSM) for optimizing, at the preliminary design level, a supersonic urbine aimed for Reusable Launching V'éhicle (RLV) propulsion istem application. Single-, (wo- and three-stage turbines 
AlAA-2000-3242

are considered with the number of design variables increasing in accordance with the number of stages. In the first step, the overall dimensions such as mean diameter and axial chords, the RPM and the number of stages are to be determined. In the second step. detail blade geometries will be optimized to achieve the best efficiency for a given overall gas path meridional geometry. This paper is limited to the preliminary optimization.

In the past such optimization tasks might take weeks to perform due to the large number of parameters involved. The systematic application of RSM computationally coupled with an appropriate curbine analysis code will in the future allow designers to cut this cycle time down to a few hours.

There are 2 types of design variables:

1. Geometric input needed (1) layout the turbine meridional geometry.

- mean diameter

- last rotor annulus areal

- blade height ratio between the $1^{\text {- }}$ ane and the last rotor blade - linear distribution of blade heights is assumed between the I" vane and the last rotor blade

- valne and hlade axial chords

2. Performance mput used an catculate the lurbine afticiency

- RPM

- number of stages

- Mlade row reaction

- work split if more han 1 tage is investigated

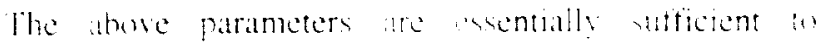

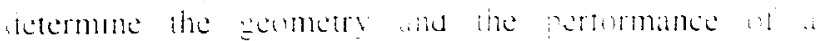
preliminary design. Is indicated in lables ! $\therefore$. lor turbine with 1 stage. 2 stages or 3 stages the number of parameters are $6.11,15$, respectively. Constraints are also part of the optimization process. There are I structural constraints. the blade centritugal stress and the disk stress. The blade centrifugal stress was constraned by a limit placed on the lumped inertia measure the product of the blade exit annulus area and the $R P M^{-}$). The disk stress was constrained by a limit placed on the pitchline velocity (the product of the RPM and the mean radius).

For rocket engine applications. maximizing the vehicle paylead for a given turbine operating condition is the ultimate objective. Any gain in turbine efficiency will be reflected in a reduced propellant consumption. thus in an increase in payload. However, higher turbine performance usually entails multistage designs, which are heavier. A proprietary weight correlation is employed to estimate the impact of the curbine $x$ holces on the overall turbopump unit weight since a slowly rotating turbine is not only heavy by itself but also imposes a significant weight penalty on the pump side. An equation expressing the relationship between these opposing effects will be employed as a criterion to guide the optimization task. As will be presented in detail later, this composite objective function describes essentially the payload increment versus turbopump efficiency and weight. It is developed based on mission profile studies, engine balance perturbation and some detailed turbopump layout and stress information gained from other proprietary programs.

\section{APPROACH}

The overall approach to determine the optimum design is shown in Figure 1. The RSM is used to model the relationship between design variables and objective/constraint functions in function approximation stage of the overall approach.

The approach of RSM is to perform a series of experiments, based on numerical analyses. semiempirical formulas, or experimental testing, for a prescribed set of design points. and to construct a global ilpproximation of the measured quantity over the design space. In this effort, numerical analysis is based on the alerodynamic design software, Heanline flow Path Generater. for rapid analyses of turbine flow fields. l sing overall turbine and stage input. the Meanline code lirst generates a candidate turbine thow path and displays a plot of the clevation view. The code, then, runs a meanline analysis. calculating gas conditions, velocity triangles. and required number of airfoils, predicted efficiency and power output. A calculation to predict lurbine weight is also included. The run time required for analysis of a three-stage turbine on the current version of the conde is less than one second on a Pentium II PC. The aulaces af pertormance losses due to antoil profile. ceondary endwall. tralling edge blockage, trailing edge shock. leading edge shock and unshrouded blade tip leakage are also included.

Second-arder polynomials atre used for the response surface approximations for which extremal points are casily found by standard constrained optimization algorithms. The main advantages of RSM over other optimization tools such as gradient-based search algorithms are that it requires minimal interfacing with the analysis tools and avoids the need for expensive derivative calculations. To construct a second-order polynomial of $V$ design varrables, the number of coefficients to be fixed are $(N+1) N+2) / 2$.

As a tirst step of the overall approach of Figure 1, a generic design box obtained by coding all design variable (1) the range $1-1,+1$ ) is considered. Coding is based on the following tormula: 
$x_{i}=\bar{x}_{i} \frac{\left(x_{\max _{1}}-x_{\min _{1}}\right)}{2}+\frac{\left(x_{\max }+x_{\min }\right)}{2}$

where $x_{i}$ : real value of the design variable $\bar{x}_{i}$ : normalized value of the design variable $x_{\max }$ : maximum real value of the design variable $x_{\text {min }}$ : minimum real value of the design variable

The coding requires the information of the maximum and minimum values for each design variable that can be obtained from Tables $1-3$.

The response surfaces of this study are generated by standard least-squares regression using $\mathrm{JMP}^{\frac{5}{2}}$, I statistical analysis software having a variety of statistical analyses functions. The global fit and prediction accuracies of the response surfaces are assessed through statistical measures such as the t-statistic, or t-ratios, mis-errot, variation ${ }^{1.2 .3}$. The t-statistic is determined by

$r=\frac{b}{\sec (b)}$

where $b_{1}$ : regression coefticient

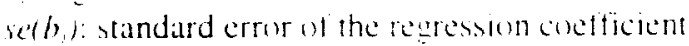
and it is glven by

ub $-i \sqrt{c}$

where $C_{1}$ : diagonal element of $(X X)$ corresponding w b. $X$ is an nxp matrix at the kevels of the independent variables where $n$ is the number of hervations and $p$ is the number at lerms in the modely

i: unbiased estimatur wh the standard deviation ot the observations and unbiased estimator of the rms-error in prediction hased on the response vartace and it is given by

$$
i=\sqrt{\sqrt{n-l}}
$$

where $e_{l}$ : difference between the observation, $y_{i}$, and the fitted value, $\hat{y}_{i}$

The $R^{-}$value is determined hy

$K-\frac{S S}{S S_{i r}}=1-\frac{S S_{i}}{S S_{w}}$

where $S S_{E}$ : sum of squares of the residuals or errors $S S_{R}$ : sum of squares due to regression
$S S_{y y}:$ total sum of squares about the mean

$S S_{w}=S S_{R}+S S_{l}$

$R^{2}$ measures the proportion of the variation in the response around the mean that can be attributed to terms in the model rather than to random error ${ }^{3} . R_{a}^{2}$ is an $R^{2}$ value adjusted to account for the degrees of freedom in the model and is given by

$$
R_{i a}^{2}=1-\frac{S S_{i:} /(n-p)}{S S_{y y} /(n-1)}=1-\left(\frac{n-1}{n-p}\right)\left(1-R^{2}\right)
$$

Since $R^{2}$ will always increase as terms are added to the model, the overall assessment of the model may be better judged from $R_{u}^{2}$.

The polynomial-based RSM techniques are effective in representing the global characteristics of the design sace. It can filter the noises associated with individual design data. On the other hand. depending on the order of polynomial employed and the shape of the actual response surface, the RSM can introduce a substantial error in certain region of the design space. An uptimization scheme requiring large amounts of data and a large evaluation time o generite meaningful results is hardly useful.

The optimization lechnique collows qualitatively that adopted previously for optimizing thid machinery such as diffuser, injector, and airfoil, is presented in Refs. ${ }^{6.9}$. The effect of numerical noise and the interaction between (FD models and RSM are addressed by Madsen et al". In the paper by Tucker et al. ${ }^{7}$ a tirst effort is made to apply RSM for infector ontimizatum. Papila et al." investigated the elfect of data size and relatuve merits between RSM ind neural networks in handling varying data characteristics. The neural network technique and the RSM are integrated to offer enhanced optimization capabilities by shyy et al.". I mann ticus in the present work is the interplay between the number of design variables and the predictive capability and input requirement of the RSM. To ascertain required predictive capability of the RSM, a two-level domain refinement approach has been adopted. As will be demonstrated in the following, the accuracy of the predicted optimal design points based on this strategy is satisfactory.

\section{DESIGN OF EXPERIMENTS (DOE)}

The response surface method is a collection of statistical and mathematical techniques useful for developing, improving, and optimizing processes and this provides an werall perspective of the system response within the design space $i$. The representation of the design space is, 
therefore, important. In order to help to minimize the effect of noise on the fitted polynomial, and to improve the representation of the design space, design of experiments (DOE) procedure can be used. There are a number of different DOE techniques reported in the literature $^{10-17}$. For example, Unal et al ${ }^{10}$ discussed the face centered composite designs and D-optimal designs for representation of the design space for wing-body configuration of a launch vehicle. They showed that $D$ optimal design provides an efficient approach for approximating model building and multidisciplinary optimization. Unal et al. ${ }^{1 i}$ studied response surface model building using orthogonal arrays in computer experiments for reusable launch vehicle and illustrated that using this technique minimizes design. development, test and evaluation cost. Similar results were obtained using three level fractional factorial experimental design ${ }^{12}$. Unal and Dean ${ }^{13}$ studied the robust design method based on the Taguchi method ${ }^{1+-15}$ to determine the optimum configuration of design parameters for performance. quality and cost. They demonstrated that using such a robust design method for selectoon of design points is a systematic and efficient approach for determining the uptimum configuration.

The face centered composite design (FCCD) creates a design space composed of eight corners of the cube. four center of faces and the center of the cube. Figure 2 shows lace centered composite desien points for three design variables. The FCCD yields $12^{2}+2 N+1$, points. where $N$ 1s the number of design variables. It is more effective when the number of design variables is modest. say. no larger than 5 or 0 . The FCCD is widely used for titting second-urder response surtace

1 D-optimal design minimizes the generalized variance.

if the estimates which is equatent w maximaing the determinant of the moment matrix. $b^{\prime}$

$$
|\mathrm{M}|=\frac{\left|\mathrm{X}^{\prime} \mathrm{X}\right|}{\mathrm{V}^{P}}
$$

The D-Optimal design approach requares the knowledge if the propertes of polynomial model in selecting the design points.

An orthogonal array (OA) is a fractional factorial matrix that assures a balanced comparison of levels of any factor or interaction of factors. Because the points are not necessarily at vertices, the orthogonal array can be more robust than the face centered cubic design. Based on the design of experiments theory. OA can significantly reduces the number of experimental contigurations.

In this study, although the majority of the work is based on the FCCD approach, alternative representations of the design space are performed by using D-Optimal design and $\mathrm{OA}$ design. We have considered 1-, 2- and 3-stage turbine. There are 6 design parameters for single- stage turbine case chosen as the mean diameter, $R P M$, blade annulus area, vane axial chord, blade axial chord, and stage reaction. For 2-stage turbine, mean diameter, $R P M$, exit blade annulus area. $1^{\text {st }}$ blade height ( $\%$ of exit blade), $1^{\text {st }}$ vane axial chord, $1^{\text {st }}$ blade axial chord, $2^{\text {nd }}$ vane axial chord, $2^{\text {nd }}$ blade axial chord, $1^{\text {st }}$ stage reaction, $2^{\text {nd }}$ stage reaction, and $1^{\text {st }}$ stage work fraction, are chosen and there are, in total, 11 design parameters. There are 15 design parameters for 3-stage case determined as mean diameter, $R P M$, exit blade annulus area, $1^{\text {st }}$ blade height (\% of exit blade), $1^{\text {st }}$ vane axial chord. $1^{\text {st }}$ blade axial chord, $2^{\text {nd }}$ vane axial chord, $2^{\text {nd }}$ blade axial chord, $3^{\text {rd }}$ vane axial chord, $3^{\text {sd }}$ blade axial chord, $1^{\text {st }}$ stage reaction, $2^{\text {nd }}$ stage reaction, $3^{\text {rd }}$ stage reaction, $1^{\text {st }}$ stage work fraction, $2^{\text {nd }}$ stage work fraction, and $3^{\text {rd }}$ stage work fraction. Table l-3 show the maximum and minimum values of these parameters as well as their baseline values.

With 6-input parameters of single-stage turbine, FCCD produces 77-data, but Meanline code produced results for 76-data excluding one unrealistic case. Therefore, 76data is used to approximate the single-stage turbine characteristics. With 11 -input parameters of 2-stage turbine, FCCD yields 2.071-data. but Meanline code produced results for 1990-data and this set is used to approximate the 2-stalge turbine characteristics. For 3stage having 15-input parameters. PCCD creates 32.799data based on the formula of $2^{1+}+2 N+1$ with $N=15$ demonstrating the curse of dimensionality. For such cases, a statistical method can be applied to reduce the number of data in an efficient way. In this effort. to reduce the data set of i-stageturbine of 15 -dimension. Doptimal design is adopted to minimize the generalized variance of the estimates. With the D-optimal criterion. the number of data is reduced to 2500: the Meanline code worked for 2235 of them. In this paper. the orthogonal arrays are also applied for the 2-stage turbine case using a public domain software developed by Owen ${ }^{18}$.

\section{THE OPTIMIZATION PROBLEMI}

The equation describing the response as given by $J M P$ is input is Excel Solver. Solver is an uptimization toolbox included with Microsoft Excel which uses the Generalized Reduced Gradient method to find the maximum or minimum of a function with given constraints.

The optimization problem at hand is a constrained optimization problem. which can be formulated as $\min \{f(x)\}$ subject $a b \leq \mathrm{x} \leq a b$. where $b$ is the lower boundary vector and $u b$ is the upper boundary vector of the design variables vector $x$. Since the goal is to maximize objective tunction therefore $f(x)$ can be written as $-g(x)$, where $g(x)$ is the objective function. Minimizing 
of $f(x)$ gives the same solution as maximizing the objective function $\boldsymbol{g}(\boldsymbol{x})$. Additional linear or nonlinear constraints can be incorporated if required.

In this study, the purpose is maximizing the turbine efficiency, $\eta$, and minimizing the overall weight, $W$, simultaneously. The response surface method can handle a multi-criteria optimization task in a straightforward manner by building a composite response surface from individual response surfaces. This composite response surface is referred to as the desirability function. The desirability function for $\eta$, i.e., $d_{i}$, can be defined which is to be maximized as

$\mathrm{d}_{1}=\left(\frac{\eta-\eta_{\min }}{\eta_{\max }-\eta_{\mathrm{mun}}}\right)^{s}$

and the desirability function for $W$. i.e... $l_{2}$. can be defined which is to be minimized as

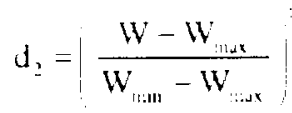

where powers $s$ and $t$ are weighting factors which are set according 10 the role of the response in composite desirability function. i.e. d. detined as follows:

$$
d=\sqrt{d_{1} \cdot d_{2}}
$$

Another way of finding optimum balues of $1 /$ and $f$ simulaneously is 10 maximize payluad increment. Jpas. which is a function al these (wi) paramelers in the following manner.

$$
\text { Jpaly }=c_{1} \times 100 \times\left(\eta-\eta_{n}\right)-\left(W-W_{n, 1}\right.
$$

where $\eta_{b}$ is the baseline efficiency and $w_{b}$ is the baseline weight. Apay function represents the amount of increalse in payload capacity. The results if both payload increment based and composite desirability funcuon hased optimization are illustrated for 1. 2, and 3-stage designs. For the composile destrability functoon based optimization, different combinations of the power of $d_{i}$ and $d_{2}$ are considered with different values of $t$ and $s$.

The pitchline speed, $V_{\text {purth }}$, and the lumped inertia measure. $d N^{2}$. are used als the design constraints when finding the optimum solutions.

$$
\begin{aligned}
& \mathrm{AN}^{2}=\text { Aann } \times \mathrm{RPM}^{2} \\
& \text { where } D \text { is meanline diameter. }
\end{aligned}
$$

\section{RESULTS AND DISCUSSION}

The properties of the response surfaces obtained for $\eta$. $W$, and $\Delta p a y$ are shown in Tables 4 and 5 for 1-,2-, and 3 stage turbine designs.

For the single-stage case, there are 28-unknown coefficients needed for constructing the $2^{\text {nd }}$-order response surface, 78 for the 2-stage and 136 for the 3 stage case. The quality of the fit can be evaluated by comparing the adjusted root mean square error (rmserror) shown in Table 5.

RSM-based approximations together with the Excel Solver to find the maximum or minimum of the objective function with a given constraints is used to find the optimum point are obtained for all cases. Different starting points are tried to avoid local maximum and the uptimum values of $\eta . W$ and $\Delta p a y$ with the corresponding design parameters are determined. Table 6 shows the optimum values of $\eta, W$ and $J p a y$ calculated for both Jpay (Eqn. 12) based optimization and composite desirability function based optimization (Eqn.11) for $(t=l, s=0),(t=0, s=l)$, and $(t=l, s=l)$ cases for singlestage turbine. The case $(t=l, s=0)$ represents the optimization based on weight only. whereas $(t=0, s=I)$ represents the optimization based on efficiency only. The results shown in this table are comparable with the curresponding Meanline runs with the highest error of $5 \%$ for Apay for single-stage turbine. Table 7 shows the uptimum values of $\eta$. $W$ and $A p a y$ calculated for both Jpay hased optimization and composite desirability luncturn based optimization fior $(t=1, s=0),(t=0, s=1)$, and $t t=1, s=1)$ cases for the 2-stage turbine design.. When the results thown in this athle are compared with the corresponding Veanlme runs at the same design parameters, it is observed that the percentage error is increased up to $13.5 \%$ for $\Delta p a y$. Table 8 shows the optimum values of $\eta, W$ and $\Delta p a y$ calculated for the 3 talge turbine with the same approach. When the results shown in this table are compared with the corresponding Heanline runs, it is observed that the percentage error is increased up to 14.0 if for Jpay indicating that the accuracy of the response surfaces constructed for this case is poor.

Because the accuracy of the response surface is less than satisfactory for 2- and 3-stage cases. we have reduced the size of the parameter space with the intention of improving the tidelity of the response surface. The details of the $1 / 5$ reduced design spaces are shown in Table 9 12. The new design space is based on the optimal values identified for $\eta$ \& $W((t=1, s=0),(t=0, s=1) \&(t=1$, $i=l /$ and $l p a r$ hased optimization cases. With these retined designed spaces, substantial improvement of the 
response surface fit accuracy is observed for 2-stage and also for 3-stage (Tables 13 and 14).

Based on the results obtained. the following observations can be made:

To ascertain required predictive capability of the RSM, a two-level domain refinement strategy has been adopted. The accuracy of the predicted optimal design points based on this approach is shown to be satisfactory.

(ii) For $\Delta$ pay-based optimization, the 2-stage turbine gives the best $\Delta$ pay result. As the number of the stage increases, we see that efficiency improves while the weight increases also. According to the formula for $\Delta$ pay, the improvement in efficiency can't compensate the penalty from higher weight. As shown in Figure 3. the mean diameter. speed. and the exit hlade area exhibit distinct trends. Specifically. the diameter decreases, speed increases, and annulus area decreases with increasing number of stages. It is interesting to observe that none of these design parameters are toward the limiting values listed in Tables 1-3. indicating that the optimal designs result from compromises between competing parametric trends. For such cases a formal iptumizer such as the present response surtace method is very userul.

(iii)

For hoth weight onl aptimizatom $1:=l, s=(1)$ and efficiency only (pomization $(t=t), s=1)$, as expected. the single-stage design gives the smallest weight. The efficiency also improves as the number of stiges increalses cee Tables 15 and 16. and figetere + tor summariess. It is interesting to see that in both cases. the electums of the bameler. yeed and annulus area are insensitwe w the number of stages. For example, for weight unly opumization $t=l$. $s=(), \quad D$ approaches minimum. and $R P M$ approaches maximum. while the annulus area is governed by the deston constrant between it and RP.H.

(w) On the other hand. Cor the efficiency only optumization $(t=f),=i)$. liur all three stage designs, the annulus area approaches maximum and $R P M$ is governed by the design constraint. The diameter, $D$, on the other hand, takes middle values within the design range (Figure 5 ).

(v) Similar (1) the one hased on Jpay, the case of $t=1, s=1)$ is also a compromise between weight and efficiency. However, because of the different mathematical formulas adopted. ditferent design selections than the ones based on $\Delta p a y$ result. It seems clear that the precise definition of the iptimal ariterion ubstantially intluence the selection of the optimal design.
In order to determine how the optimum solution for $\Delta p a y$ changes as the weighting constants, $t$ and $s$, are changing, three designs of $(t=1, s=0),(t=0, s=1)$ and $(t=1, s=1)$ denoted as $\Omega_{1}, \Omega_{2}$ and $\Omega_{3}$, respectively, are selected as candidate vertex points to define a plane referred as $\alpha$ Plane as follows.

$\Omega=\alpha_{1} \Omega_{1}+\alpha_{2} \Omega_{2}+\alpha_{3} \Omega_{3}$

where $\sum_{i} \alpha_{i}=1$ and $0 \leq \alpha_{i} \leq 1$ for $i=1,2,3$

Equation 12 was used to obtain 66 design points distributed on the alpha plane for 2-stage turbine. Figure 6 illustrates the contour plots over the $\alpha$-Plane for optimum $\Delta p a y$. This figure shows that $\Delta p a y$ reaches its maximum value for a range of $t, 0<t<1$ for $s=1$.

\section{ORTHOGONAL ARRAYS FOR 2-STAGE TURBINE DESIGN}

Although the majority of the present work is based on the FCCD approach, orthogonal arrays are constructed to investigate the efficiency of orthogonal array designs in representing the design space for 2-stage turbine. For this purpose. 249 design points are selected using OA designs. Table 17 shows the comparison of the statistics If the second-order response surfices generated for $\eta, W$ and $\Delta p a y$ by using 1990-data generated by tace centered composite design and 249-data selected by OA method. This table illustrates that the fidelity of the response surface generated tor design space of 249 data, based on "rthogonal arrays. are comparable with that of 1990 data based on the face centered criterion. The response surface models are also assessed by using 78-test data to determine the predictive accuracy of these models. Table Is presents that the cesting rms-errors of response surfaces generated are $1.65 \%$ for $\eta$ and $0.96 \%$ for $W$ using 249-data, and $1.67 \%$ for $\eta$ and $1.21 \%$ for $W$ using 1990-data. The results of optimization based on $\Delta$ pay and composite desirability tunction of $\eta$ \& $W$ with 249-data selected by orthogonal arrays are shown in Table 19 for the original design space and in Table 20 for the retined design space. When these results are compared with the results of 1990-data presented in Tables 7 and 13, it is observed that the optimum $\eta, W$ and 4 pay are largely consistent. However, it is also observed from Figure 7 which shows the comparison of the design variables for optimization based in (Apay). some of the design variables are different even though optimum $\eta, W$ and Jpay are consistent. This shows that there are multiple points in the design space which yield comparable performance. Nevertheless. it remains true that the twostage turbine is most sutable from a payload point of view.

6 


\section{CONCLUDING REMARKS}

In summary, the result of the RSM computation indicates that indeed the efficiency rises quickly from 1 stage to 2 stages but the increase is much less pronounced with 3 stages. A 1-stage turbine performs poorly under the engine balance boundary condition. A significant portion of kinetic energy is lost at the turbine discharge of the 1stage design due to high pressure ratio and high energy content, mostly hydrogen, of the working tluid. Adding a $2^{\text {nd }}$ stage recovers most of that wasted energy resulting in much better efficiency for a 2 -stage turbine. An extra $3^{\text {rd }}$ stage only improves the efficiency slightly. Understandably, the turbopump weight also increases substantially from 1 to 3 stages even though the 3-stage turbine diameter is smaller. The smaller diameter is the direct outcome of higher $R P M$ that is the result of lower exit annulus area satisfying the constraint defined for $A N^{2}$. The exit annulus area is smaller because of the lower pressure ratio per stage. However, the 3-stage turbine is much longer and requires a change in bearing configuration that adds significantly into the overall weight. The optimum 2-stage turbine resulting from the RSM optimization is consistent with a design produced by an experienced engineer; namely, that most of the work is done by the $1^{\prime \prime}$ stage at very low reatction. By varying from 1-10 2-to 3-stages. We observe that while the size of the tratning data increase naturally with the number of design variables, the actual need is case dependent. Furthermore, it seems that the selection of the data distribution can be more critical than the data size. Present investigation has also demonstrated that the criteriat for selecting the data base exhibit significant impact on the efficiency and effectiveness of the construction of the response surfice.

\section{ACKNOWLEDGEMENT}

This present work is supported by NASA Marshall Space Flight Center (Grant \#: NAG8-1251). We have also recerved valuable comments from Professor Raphael Hattha of the University of Florida.

\section{REFERENCES}

'Myers, R. H. and Montgomery, D. C., Response Surface Methodology - Process and Product Optimization Using Designed Experiments, New York: John Wiley \& Sons, Inc., 1995.

2JMP version 3. Statistics And Graphics Guide. SAS Institute Inc., 1998.

'Sloan. J., "Airfoil and Wing Planform Optimization for Low Reynolds Number Fight Vehicles." Master of . Science Thesis, University of Florida. 1998.
${ }^{4}$ Madsen, J.I., "Design Optimization of Internal Flow Devices," Philosophy of Doctorate Thesis, Aalborg University, 1998.

${ }^{5}$ Microsoft Corporation (1985-1996). Microsoft Excel 97.

${ }^{6}$ Madsen, J.I., Shyy, W. and Haftka, R.T., "Response Surface Techniques for Diffuser Shape Optimization," accepted for publication in AIAA Journal, 1999.

${ }^{7}$ Tucker, P.K., Shyy, W. and Sloan, J.G., "An Integrated Design/Optimization Methodology for Rocket Engine Injectors." AIAA/SAE/ASME/ASEE 34th Joint Propulsion Conference, Paper No. 98-3513, July 13-15, 1998.

${ }^{8}$ Papila, N., Shyy, W., Fitz-Coy, N. and Haftka, R.T., "Assessment of Neural Net and Polynomial-Based Techniques for Aerodynamic Applications," AIAA 17th Applied Aerodynamics Conference. Paper No. 99-3167, 1999.

"Shyy, W., Tucker, P.K. and Vaidyanathan, R.. "Response Surface and Neural Network Techniques for Rocket Engine Injector Optimization," AIAA/SAE/ASME/ASEE 35th Joint Propulsion Conference, Paper No. 99-2+55. June 20-24. 1999

"Inal. R.. Lepsch. R. A.. and McMillin. M. L.. "Response Surface Model Building and Multidisciplinary Optimization using D-Optımal Designs," $7^{\text {th }}$ AIAA/USAF/NASA/ISSMO SYmposium on Multidisciplinary Analysis and Optimization. Paper No. 98-4759. September 2-4. 1998

${ }^{1}$ Unal. R.. Braun. R. D., Moore. A.A. and Lepsch. R.A.. Response Surtace Model Building I Ising Orthogonal Arrays for Computer Experiments." $19^{\text {th }}$ Anmual International Conference of the International Society of Parametric Analysis, New Orleans, Louisiana, May 22. 30. pp.13. 1997.

${ }^{2}$ Unal. R.. Braun. R. D.. Moore. A. A.. and Lepsch. R.A. "Design Optimization on Cost Basis Using Taguchi"s Orthogonal Arrays" Proceedings of the Annual American Society for Engineering Management (ASEM) Conference, October, 1996.

${ }^{13}$ Unal, R., and Dean, E. B., "Design For Cost And Quality: The Robust Design Approach." http://mijuno.larc nasa.gov/palp/robdes/robdes.html, 1995.

"Unal, R., and Dean, E. B., "Taguchi Approach to Design Optimization for Quality and Cost: An Overview." Proceedings of the International Society of 
Parametric Analysts $13^{\text {th }}$ Annual Conference, New Orleans, Louisiana, May 21-24, 1991.

${ }^{15}$ Dean, E. B., "Taguchi Methods from the Perspective of Competitive Advantage," http://akao.larc.nasa.gov/dfc/ tm.html. 1995.

${ }^{16}$ Balabanov, V.O., Giunta, A.A., Golovidov, O., Grossman, B., Mason, W.H., Watson, L.T., and Haftka, R.T., "Reasonable Design Space Approach to Response Surface Approximation," Journal of Aircraft, 36(1), pp. 308-315, 1999.

${ }^{17}$ Trosset, M. W., and Torczon. V.. "Numerical Optimization Using Computer Experiments," NASA CR201724 ICASE Report No.9738, pp.16, August 1997.
${ }^{18}$ Owen, A., "Orthogonal Arrays for: Computer Experiments, Visualization, and Integration in high dimensions," http://src.doc.ic.ac.uk/public/pub/Mirrors/ lib.stat.cmu.edu/designs/owen.readme, 1994.

${ }^{19}$ Ladson, L.S., Waren, A. D., Jain, A., and Ratner, M., "Design and Testing of a Generalized Reduced Gradient Code for Non-linear Programming," ACM Transactions on Mathematical Software, Vol. 4, No. 1, pp.51-56, 1978.

${ }^{20}$ Venter, G., Haftka, R.T., and Starnes, J.H., Jr. "Construction of Response Surface Approximation for Design Optimization," AlAA Journal, 36(12), pp. 22422249, 1998.

Table 1. Design Space for Single-Stage Turbine (All geometric design variables are normalized by the baseline values)

\begin{tabular}{lcc}
\hline Variable & Lower Limit & Upper Limit \\
\hline Mean Diameter. D & 0.50 & 1.50 \\
Speed, RPM & 0.70 & 1.30 \\
Blade Annulus Area. A & 0.70 & 1.30 \\
Vane Axial Chord. & 0.39 & 1.71 \\
Blade Axial Chord. & 0.26 & 1.14 \\
Stage Reaction, sr & $0.0 \%$ & $50 \%$ \\
\hline \hline
\end{tabular}

Table 2. Design Space for 2-Stage Turbine I All geometric design variables are normalized by the baseline values

\begin{tabular}{|c|c|c|}
\hline Variable & Lower Limit & Upper Limit \\
\hline Mean Diameter, D & 0.50 & 1.50 \\
\hline Speed. $R P M$ & 0.70 & 1.30 \\
\hline Blade Annulus Area. $A_{\text {ann }}$ & 0.70 & 1.30 \\
\hline 1" Blade Height ( $\%$ of Exit Blade), $h_{1}$ & 0.90 & 1.50 \\
\hline $1^{\text {st }}$ Vane Axial Chord. $c_{v 1}$ & 0.39 & 1.71 \\
\hline 1" Blade Axial Chord. $c_{b l}$ & 0.26 & 1.14 \\
\hline $2^{\text {nd }}$ Vane Axial Chord, $c_{v 2}$ & 0.21 & $1 .+1$ \\
\hline $2^{\text {nd }}$ Blade Axial Chord, $c_{b 2}$ & 0.17 & 1.13 \\
\hline $1^{\text {st }}$ Stage Reaction, $\mathrm{sr}_{1}$ & $0.0 \%$ & $50 \%$ \\
\hline $2^{\text {nd }}$ Stage Reaction, $\mathrm{sr}_{2}$ & $0.0 \%$ & $50 \%$ \\
\hline $1^{\text {st }}$ Work Fraction, wf & $50 \%$ & $85 \%$ \\
\hline
\end{tabular}


AIAA-2000-3242

Table 3. Design Space for 3-Stage Turbine (All geometric design variables are normalized by the baseline values)

\begin{tabular}{|c|c|c|}
\hline Variable & Lower Limit & Upper Limit \\
\hline Mean Diameter, $\mathrm{D}$ & 0.50 & 1.50 \\
\hline Speed, $R P M$ & 0.70 & 1.30 \\
\hline Blade Annulus Area, $A_{i n n}$ & 0.70 & 1.30 \\
\hline $1^{\text {st }}$ Blade Height ( $\%$ of Exit Blade), $h_{1}$ & 0.90 & 1.50 \\
\hline $1^{\text {st }}$ Vane Axial Chord, $c_{v 1}$ & 0.39 & 1.71 \\
\hline $1^{\text {st }}$ Blade Axial Chord, $c_{b 1}$ & 0.26 & 1.14 \\
\hline $2^{\text {nd }}$ Vane Axial Chord, $c_{v 2}$ & 0.21 & 1.41 \\
\hline $2^{\text {nd }}$ Blade Axial Chord, $c_{b 2}$ & 0.17 & 1.13 \\
\hline $3^{\text {rd }}$ Vane Axial Chord, $c_{v ;}$ & 0.21 & 1.41 \\
\hline $3^{\text {rd }}$ Blade Axial Chord, $c_{h ;}$ & 0.17 & 1.13 \\
\hline $1^{\text {st }}$ Stage Reaction, $\mathrm{sr}_{1}$ & $0.0 \%$ & $50 \%$ \\
\hline $2^{\text {nd }}$ Stage Reaction, $\mathrm{sr}_{2}$ & $0.0 \%$ & $50 \%$ \\
\hline $3^{\text {rd }}$ Stage Reaction. $\mathrm{sr}_{3}$ & $0.0 \%$ & $50 \%$ \\
\hline $1^{\text {st }}$ Work Fraction, wf & $40 \%$ & $80 \%$ \\
\hline $2^{\text {nd }}$ Work Fraction, wf & $30 \%$ & $10 \%$ \\
\hline
\end{tabular}

Table 4. Response Surface Summary tor 1. 2 and 3-Stage Turbine

\begin{tabular}{lccc}
\hline & No. of Design Parameters & No. of Coefficients & No. of Design Points \\
\hline 1-Stage & 6 & 28 & 76 \\
2-Stage & 11 & 78 & 1990 \\
3-Stage & 15 & 136 & 2235 \\
\hline \hline
\end{tabular}

Table 5. The quality of the Second-Order Response Surtace obtained for $\eta, W$, and $\Delta p a y$ 1. 2 and 3-Stage Turbine (Mean values of $\eta$. W and $\Delta p a y$ are normalized by the baseline values)

\begin{tabular}{|c|c|c|c|c|}
\hline & & $\eta$ & $W$ & $\Delta$ pay \\
\hline \multirow{4}{*}{ 1-Stage } & $\mathrm{R}^{2}$ & 0.998 & 0.999 & 0.998 \\
\hline & $\mathrm{Ra}^{2}$ & 0.997 & 0.999 & 0.997 \\
\hline & ms-aror & $2.50 \%$ & $0.82 \%$ & $4.09 \%$ \\
\hline & Mean & 0.57 & 0.60 & -0.43 \\
\hline \multirow{4}{*}{ 2-Stage } & $\mathrm{R}^{-}$ & 0.995 & 0.996 & 0.995 \\
\hline & $\mathrm{Ral}^{{ }^{\prime}}$ & 0.994 & 0.996 & 0.995 \\
\hline & rms-error & $1.31 \%$ & $2.56 \%$ & $9.58 \%$ \\
\hline & Mean & 0.78 & 0.86 & -0.24 \\
\hline \multirow{4}{*}{ 3-Stage } & $\mathrm{R}^{2}$ & 0.989 & 0.989 & 0.994 \\
\hline & $\mathrm{Ra}^{2}$ & 0.988 & 0.988 & 0.994 \\
\hline & rms-ermor & $2.0 \%$ & $2.9 \%$ & $8.4 \%$ \\
\hline & Mean & 0.89 & $1 .+1$ & -0.26 \\
\hline
\end{tabular}


Table 6. Optimization based on $\Delta p a y$ and composite desirability function of $\eta$ and $W$ for single-stage turbine (All geometric design variables and output parameters are normalized by the baseline values)

\begin{tabular}{|c|c|c|c|c|c|c|c|c|c|}
\hline & $\eta_{\text {opt }}$ & $W_{\text {opt }}$ & $\Delta$ pay $_{\text {opt }}$ & $\mathrm{D}$ & $R P M$ & $\mathrm{~A}_{\text {ann }}$ & $c_{v}$ & $c_{b}$ & $\mathbf{s r}$ \\
\hline $\operatorname{RSM}(\Delta p a y)$ & 0.766 & 0.731 & -0.214 & \multirow{2}{*}{1.181} & \multirow{2}{*}{0.975} & \multirow{2}{*}{1.166} & \multirow{2}{*}{1.706} & \multirow{2}{*}{0.880} & \multirow{2}{*}{0} \\
\hline \begin{tabular}{|l|} 
Meanline \\
\end{tabular} & 0.797 & 0.733 & -0.193 & & & & & & \\
\hline Error $\%$ of mean & 2.9 & 0.3 & 4.8 & & & & & & \\
\hline $\operatorname{RSM}(t=1, s=0)$ & 0.399 & 0.407 & -0.611 & \multirow{2}{*}{0.502} & \multirow{2}{*}{1.284} & \multirow{2}{*}{0.699} & \multirow{2}{*}{0.394} & \multirow{2}{*}{0.264} & \multirow{2}{*}{0.5} \\
\hline Meanline & 0.383 & 0.402 & -0.623 & & & & & & \\
\hline Error \% of mean & 1.8 & 1 & 2.7 & & & & & & \\
\hline $\operatorname{RSM}(t=0, s=1)$ & 0.781 & 0.762 & -0.216 & \multirow{2}{*}{1.260} & \multirow{2}{*}{0.915} & \multirow{2}{*}{1.300} & \multirow{2}{*}{1.575} & \multirow{2}{*}{0.880} & \multirow{2}{*}{0} \\
\hline Meanline & 0.797 & 0.762 & -0.199 & & & & & & \\
\hline Error \% of mean & 2.2 & 0.03 & 3.8 & & & & & & \\
\hline $\operatorname{RSM}(t=I, s=I)$ & 0.702 & 0.583 & -0.261 & \multirow{2}{*}{0.895} & \multirow{2}{*}{1.284} & \multirow{2}{*}{0.699} & \multirow{2}{*}{1.706} & \multirow{2}{*}{0.264} & \multirow{2}{*}{0} \\
\hline Meanline & 0.718 & 0.588 & -0.239 & & & & & & \\
\hline
\end{tabular}

\begin{tabular}{|l|l|}
\hline Error \% of mean & 3.1 \\
\hline
\end{tabular}

Table 7. Optimization based on $\Delta p a y$ and composite desirability function of $\eta$ and $W$ for 2 -stage turbine for original design space (All geometric design variables and output parameters are normalized by the baseline values)

\begin{tabular}{|c|c|c|c|c|c|c|c|c|c|c|c|c|c|c|}
\hline & $\eta_{\text {opt }}$ & $W_{\text {opt }}$ & $\Delta$ pay $_{\text {opt }}$ & $D$ & $R P M$ & $A_{\text {ann }}$ & $h_{1}$ & $\mathrm{c}_{\mathrm{vl}}$ & $\dot{L}_{\mathrm{v} 2}$ & $c_{b l}$ & $c_{b 2}$ & $\mathrm{sr}_{\mathrm{l}}$ & $\mathrm{sr}_{2}$ & $w_{f i}$ \\
\hline $\mathbf{R S M}(\Delta p a y)$ & 1.10 & 1.05 & 0.11 & \multirow{2}{*}{1.16} & \multirow{2}{*}{0.99} & \multirow{2}{*}{1.14} & \multirow{2}{*}{1.50} & \multirow{2}{*}{1.57} & \multirow{2}{*}{0.97} & \multirow{2}{*}{0.71} & \multirow{2}{*}{0.68} & \multirow{2}{*}{0} & \multirow{2}{*}{0.50} & \multirow{2}{*}{0.85} \\
\hline Meanline & 1.12 & 1.05 & 0.14 & & & & & & & & & & & \\
\hline Error "rof mean & 2.50 & 0.00 & 10.60 & & & & & & & & & & & \\
\hline $\operatorname{RSM}(t=1, s=0)$ & 0.65 & 0.66 & -0.34 & \multirow{2}{*}{0.50} & \multirow{2}{*}{1.27} & \multirow{2}{*}{0.70} & \multirow{2}{*}{1.50} & \multirow{2}{*}{1.71} & \multirow{2}{*}{1.76} & \multirow{2}{*}{0.92} & \multirow{2}{*}{1.13} & \multirow{2}{*}{0.50} & \multirow{2}{*}{0.50} & \multirow{2}{*}{0.50} \\
\hline Meanline & 0.65 & 0.65 & -0.35 & & & & & & & & & & & \\
\hline Error \%of mean & 1.10 & 0.60 & 4.00 & & & & & & & & & & & \\
\hline $\operatorname{RSM}(t=1), s=1)$ & 1.10 & 1.10 & 0.11 & \multirow{2}{*}{1.24} & \multirow{2}{*}{0.92} & \multirow{2}{*}{1.30} & \multirow{2}{*}{1.50} & \multirow{2}{*}{1.4} & \multirow{2}{*}{1.06} & \multirow{2}{*}{0.71} & \multirow{2}{*}{0.79} & \multirow{2}{*}{0} & \multirow{2}{*}{0} & \multirow{2}{*}{0.80} \\
\hline Meanline & 1.13 & 1.10 & 0.14 & & & & & & & & & & & \\
\hline Error $\%$ cot mean & 3.30 & 0.41 & 13.50 & & & & & & & & & & & \\
\hline $\operatorname{RSM}(t=1, s=1)$ & 0.99 & 0.85 & 1). .03 & \multirow{2}{*}{0.91} & \multirow{2}{*}{1.27} & 070 & 150 & 1 & 170 & (1) 55 & 113 & 0 & 0 & 050 \\
\hline Meanline & 0.99 & 0.84 & 0.03 & & & & & & & & & & & \\
\hline Error cot mean & 0.30 & 1.70 & 0.40 & & & & & & & & & & & \\
\hline
\end{tabular}

Table 8. Optimization hased on $J p a v$ and composite desirability tunction of $\eta$ and $W$ for 3 -stage turbine for original design space ( $N$ ll geometric design variables and output parameters are normalized by the baseline values)

\begin{tabular}{|c|c|c|c|}
\hline & $\eta_{\text {not }}$ & $W_{\text {opt }}$ & $\Delta p a y_{o p t}$ \\
\hline $\mathbf{R S M}(\Delta p a y)$ & 1.24 & 1.62 & 0.14 \\
\hline Meanline & 1.21 & 1.57 & 0.10 \\
\hline Error \%of mean & +.72 & 3.52 & 14.59 \\
\hline$\overline{\operatorname{RSM}}(t=l, s=0)$ & 0.85 & 1.13 & -0.23 \\
\hline Meanline & 0.83 & 1.13 & -0.26 \\
\hline Error \%of mean & 2.13 & 0.34 & $1+.39$ \\
\hline$\overline{\operatorname{RSM}}(t=0, s=1)$ & 1.26 & 1.74 & 0.12 \\
\hline Meanline & 1.23 & 1.69 & 0.09 \\
\hline Error \%of mean & +.27 & 3.10 & 13.54 \\
\hline$\overline{\operatorname{RSM}(t=1, s=1)}$ & 1.08 & 1.33 & 0.05 \\
\hline Meintine - & 1.10 & 1.34 & 0.04 \\
\hline Error Trof mean & 2.16 & 0.59 & 4.11 \\
\hline
\end{tabular}




\begin{tabular}{|c|c|c|c|c|c|c|c|c|c|c|c|c|c|c|c|}
\hline & D & $R P M$ & $A_{\text {ann }}$ & $h_{1}$ & $c_{\mathrm{v} 1}$ & $c_{\sqrt{ } 2}$ & $c_{\mathrm{v} 3}$ & $c_{b 1}$ & $c_{b 2}$ & $c_{b 3}$ & $\mathrm{sr}_{1}$ & $\mathbf{s \tau _ { 2 }}$ & $\mathrm{sr}_{3}$ & $w f_{1}$ & $w_{2}$ \\
\hline RSM ( $\Delta p a y)$ & 1.07 & 1.07 & 0.98 & 1.50 & 1.59 & 1.09 & 0.87 & 0.56 & 1.02 & 0.89 & 0 & 0.5 & 0.5 & 0.6 & 0.3 \\
\hline $\operatorname{RSM}(t=l, s=0)$ & 0.50 & 1.28 & 0.70 & 0.90 & 1.71 & 1.76 & 1.41 & 0.73 & 1.41 & 0.17 & 0.5 & 0.5 & 0.5 & 0.4 & 0.3 \\
\hline $\operatorname{RSM}(t=0, s=1)$ & 1.19 & 0.96 & 1.20 & 1.50 & 1.44 & 1.06 & 0.78 & 0.56 & 0.99 & 0.90 & 0 & 0.5 & 0.5 & 0.6 & 0.3 \\
\hline $\operatorname{RSM}(t=l, s=l)$ & 0.91 & 1.29 & 0.70 & 1.50 & 1.71 & 0.62 & 0.78 & 0.17 & 0.21 & 1.13 & 0 & 0 & 0 & 0.6 & 0.1 \\
\hline
\end{tabular}

Table 9. Upper and Lower Limits of the Design Parameters of the refined designed spaces for 2-stage turbine (All geometric design variables are normalized by the baseline values)

\begin{tabular}{lcccccccccccc}
\hline & & $\mathrm{D}$ & $R P M$ & $\mathrm{~A}_{\mathrm{ann}}$ & $\mathrm{h}_{1}$ & $\mathrm{c}_{\mathrm{v} 1}$ & $\mathrm{c}_{\mathbf{v} 2}$ & $\mathrm{c}_{\mathrm{b} 1}$ & $\mathrm{c}_{\mathrm{b} 2}$ & $\mathbf{s r}_{\mathbf{1}}$ & $\mathbf{s r}_{\mathbf{2}}$ & $\mathbf{w}_{\mathbf{n}}$ \\
\hline Original & $\mathrm{Max}$ & 1.50 & 1.30 & 1.30 & 1.50 & 1.71 & 1.76 & 0.92 & 1.13 & 0.50 & 0.50 & 0.85 \\
& $\mathrm{Min}$ & 0.50 & 0.70 & 0.70 & 0.90 & 0.39 & 0.26 & 0.21 & 0.17 & 0.00 & 0.00 & 0.50 \\
Refined & $\mathrm{Max}$ & 1.26 & 1.05 & 1.20 & 1.50 & 1.71 & 1.11 & 0.79 & 0.79 & 0.05 & 0.50 & 0.85 \\
$(\Delta$ pay) & $\mathrm{Min}$ & 1.06 & 0.93 & 1.08 & 1.44 & 1.44 & 0.81 & 0.64 & 0.60 & 0.00 & 0.45 & 0.82 \\
Refined & $\mathrm{Max}$ & 0.60 & 1.30 & 0.76 & 1.50 & 1.71 & 1.76 & 0.92 & 1.13 & 0.50 & 0.50 & 0.54 \\
$(t=l, s=0)$ & $\mathrm{Min}$ & 0.50 & 1.21 & 0.70 & 1.44 & 1.57 & 1.61 & 0.85 & 1.03 & 0.45 & 0.45 & 0.50 \\
Retined & $\mathrm{Max}$ & 1.34 & 0.98 & 1.30 & 1.50 & 1.63 & 1.20 & 0.76 & 0.90 & 0.05 & 0.05 & 0.82 \\
$(t=0, s=1)$ & $\mathrm{Min}$ & 1.14 & 0.86 & 1.24 & 1.44 & 1.36 & 0.91 & 0.62 & 0.70 & 0.00 & 0.00 & 0.75 \\
Retined & $\mathrm{Max}$ & 1.00 & 1.30 & 0.76 & 1.50 & 1.71 & 1.76 & 0.92 & 1.13 & 0.05 & 0.05 & 0.54 \\
$(t=1, s=1)$ & $\mathrm{Min}$ & 0.80 & 1.21 & 0.70 & 1.44 & 1.57 & 1.61 & 0.80 & 1.03 & 0.00 & 0.00 & 0.50 \\
\hline
\end{tabular}

Table 10. Center Coordinates of the refined designed spaces for 2-stage turbine (All geometric design variables are normalized by the baseline values)

\begin{tabular}{lccccccccccc}
\hline & $\mathrm{D}$ & $R P M$ & $\mathrm{~A}_{\text {ann }}$ & $\mathrm{h}_{1}$ & $\mathrm{c}_{\mathrm{v} 1}$ & $\mathrm{c}_{\mathrm{v} 2}$ & $\mathrm{c}_{\mathrm{b} 1}$ & $\mathrm{c}_{\mathrm{b} 2}$ & $\mathrm{sr}_{1}$ & $\mathrm{sr}_{2}$ & $\mathrm{w}_{\mathrm{f} 1}$ \\
\hline Original & 0 & 0 & 0 & 0 & () & 0 & 0 & 0 & 0 & 0 & 0 \\
Refined $(\Delta p a y)$ & 1.16 & 0.99 & 1.14 & 1.50 & 1.57 & 0.97 & 0.71 & 0.68 & 0 & 0.5 & 0.85 \\
Refined $(t=l . s=0)$ & 0.50 & 1.27 & 0.70 & 1.50 & 1.71 & 1.76 & 0.92 & 1.13 & 0.5 & 0.5 & 0.5 \\
Refined $(t=0, s=1)$ & 1.24 & 0.92 & 1.30 & 1.50 & 1.50 & 1.06 & 0.69 & 0.80 & 0.0 & 0.0 & 0.78 \\
Retined $(t=l . s=l)$ & 0.91 & 1.27 & 0.70 & 1.50 & 1.71 & 1.76 & 0.85 & 1.13 & 0 & 0 & 0.50 \\
\hline
\end{tabular}

Table 11. Upper and Lower Limits of the Design Parameters of the refined designed spaces for 3-stage turbine (All geometric design variables are normalized by the baseline values)

\begin{tabular}{|c|c|c|c|c|c|c|c|c|c|c|c|c|c|c|c|c|}
\hline & & D & $R P M$ & $A_{a n n}$ & $h_{1}$ & $\mathrm{c}_{\mathrm{vl}}$ & $c_{\mathrm{v} 2}$ & $c_{\mathrm{v} 3}$ & $c_{b 1}$ & $c_{b 2}$ & $\mathcal{c}_{\mathrm{b} 3}$ & $\mathrm{sr}_{1}$ & $\mathrm{~s} r_{2}$ & $\mathrm{Sr}_{3}$ & $\mathrm{wf}_{1}$ & $\mathrm{wf}_{2}$ \\
\hline \multirow{2}{*}{ Original } & Max & 1.50 & 1.30 & 1.30 & 1.50 & 1.71 & 1.76 & 1.41 & 0.73 & 1.41 & 1.13 & 0.5 & 0.5 & 0.5 & 0.8 & 0.3 \\
\hline & & & & & & & & & & & & 0.0 & 0.0 & 0.0 & 0.4 & 0.1 \\
\hline & & & & & & 1.71 & & & & & & 0.05 & 0.50 & 0.50 & 0.62 & 0.30 \\
\hline & & & & & & 1.46 & 0.94 & 0.7 & & 90 & 79 & .00 & .45 & 45 & 0.56 & 0.26 \\
\hline & & & & & & 1.71 & 1.76 & 1.4 & 0.7 & & 0.26 & .50 & 0.50 & .50 & 0.44 & 0.30 \\
\hline & Min & & & & & 1.5 & 1.6 & 1.29 & 0.68 & 1.2. & 0.17 & .45 & 0.45 & 0.45 & 0.40 & 0.28 \\
\hline & & & & & & 1.6 & 1.18 & 0.93 & .60 & 1.10 & 0.99 & 0.05 & 0.50 & 0.50 & 0.62 & 0.30 \\
\hline & & & & & & & 0.88 & 0.6 & 0.49 & 0.86 & 0.80 & 0.00 & 0.45 & 0.45 & 0.56 & 0.26 \\
\hline & & & 1.30 & 76 & 1.50 & 1.71 & 0.74 & 0.88 & 0.23 & 0.3 & 1.13 & 0.05 & 0.05 & 0.05 & 0.64 & 0.14 \\
\hline$=1, s=11$ & Min & 0.80 & 1.23 & 0.70 & 1.44 & 1.57 & 0.44 & 0.64 & 0.17 & 0.21 & 1.03 & 0.00 & 0.00 & 0.00 & 0.58 & 0.10 \\
\hline
\end{tabular}


Table 12. Center Coordinates of the refined designed spaces for 3 -stage turbine (All geometric design variables are normalized by the baseline values)

\begin{tabular}{lccccccccccccccc}
\hline & $\mathrm{D}$ & $\boldsymbol{R P M}$ & $\mathrm{A}_{\mathrm{ann}}$ & $\mathrm{h}_{1}$ & $\mathrm{c}_{\mathrm{v} 1}$ & $\mathrm{c}_{\mathrm{v} 2}$ & $\mathrm{c}_{\mathrm{v} 3}$ & $\mathrm{c}_{\mathrm{bl}}$ & $\mathrm{c}_{\mathrm{b} 2}$ & $\mathrm{c}_{\mathrm{b} 3}$ & $\mathrm{sr}_{1}$ & $\mathrm{sr}_{2}$ & $\mathrm{sr}_{3}$ & $\mathbf{w f}_{1}$ & $\mathrm{wf}_{2}$ \\
\hline Original & 0 & 0 & 0 & 0 & 0 & 0 & 0 & 0 & 0 & 0 & 0 & 0 & 0 & 0 & 0 \\
Refined $(\Delta$ pay $)$ & 1.07 & 1.07 & 0.98 & 1.50 & 1.57 & 1.06 & 0.85 & 0.56 & 0.99 & 0.90 & 0.0 & 0.5 & 0.5 & 0.6 & 0.3 \\
Refined $(t=l, s=0)$ & 0.50 & 1.28 & 0.70 & 0.90 & 1.71 & 1.76 & 1.41 & 0.73 & 1.41 & 0.17 & 0.5 & 0.5 & 0.5 & 0.4 & 0.3 \\
Refined $(t=0, s=I)$ & 1.19 & 0.96 & 1.20 & 1.50 & 1.44 & 1.06 & 0.78 & 0.56 & 0.99 & 0.90 & 0.0 & 0.5 & 0.5 & 0.6 & 0.3 \\
Refined $(t=l, s=l)$ & 1.00 & 1.00 & 1.00 & 1.20 & 1.05 & 1.06 & 0.85 & 0.45 & 0.85 & 0.68 & 0.3 & 0.3 & 0.3 & 0.6 & 0.2 \\
\hline
\end{tabular}

Table 13. Optimization based on $\Delta p a y$ and composite desirability function of $\eta$ and $W$ for 2-stage turbine for refined design space (All geometric design variables and output parameters are normalized by the baseline values)

\begin{tabular}{|c|c|c|c|c|c|c|c|c|c|c|c|c|c|c|}
\hline & $\eta_{\text {opt }}$ & $\bar{W}_{\text {opt }}$ & $\Delta$ pay $_{\text {opt }}$ & $\mathrm{D}$ & $R P M$ & $A_{\text {ann }}$ & $h_{1}$ & $c_{\mathrm{v} 1}$ & $\mathrm{c}_{\mathrm{v} 2}$ & $c_{b 1}$ & $c_{b 2}$ & $\mathbf{s r}_{1}$ & $\mathbf{s r}_{2}$ & $\mathbf{w}_{\mathrm{f}}$ \\
\hline $\operatorname{RSM}(\Delta p a y)$ & 1.13 & 1.04 & 0.15 & \multirow{2}{*}{1.12} & \multirow{2}{*}{1.02} & \multirow{2}{*}{1.08} & \multirow{2}{*}{1.50} & \multirow{2}{*}{1.44} & \multirow{2}{*}{0.79} & \multirow{2}{*}{0.71} & \multirow{2}{*}{0.62} & \multirow{2}{*}{0.1} & \multirow{2}{*}{0.5} & \multirow{2}{*}{0.9} \\
\hline Meanline & 1.13 & 1.04 & 0.15 & & & & & & & & & & & \\
\hline Error $\%$ of mean & 0.03 & 0.02 & 0.16 & & & & & & & & & & & \\
\hline $\operatorname{RSM}(t=1, s=0)$ & 0.65 & 0.65 & -0.35 & \multirow{2}{*}{0.50} & \multirow{2}{*}{1.27} & \multirow{2}{*}{0.70} & \multirow{2}{*}{1.50} & \multirow{2}{*}{1.71} & \multirow{2}{*}{1.76} & \multirow{2}{*}{0.92} & \multirow{2}{*}{1.13} & \multirow{2}{*}{0.5} & \multirow{2}{*}{0.5} & \multirow{2}{*}{0.5} \\
\hline Meanline & 0.65 & 0.65 & -0.35 & & & & & & & & & & & \\
\hline Error \%of mean & 0.00 & 0.00 & 0.01 & & & & & & & & & & & \\
\hline $\operatorname{RSM}(t=0, s=1)$ & 1.15 & 1.10 & 0.15 & \multirow{2}{*}{1.23} & \multirow{2}{*}{0.93} & \multirow{2}{*}{1.30} & \multirow{2}{*}{1.50} & \multirow{2}{*}{1.31} & \multirow{2}{*}{0.88} & \multirow{2}{*}{0.71} & \multirow{2}{*}{0.73} & \multirow{2}{*}{0.1} & \multirow{2}{*}{0} & \multirow{2}{*}{0.8} \\
\hline Meanline & 1.15 & 1.10 & 0.15 & & & & & & & & & & & \\
\hline Error \%of mean & 0.02 & 0.01 & 0.09 & & & & & & & & & & & \\
\hline $\operatorname{RSM}(t=1, s=1)$ & 1.00 & 0.85 & 0.04 & \multirow{2}{*}{0.91} & \multirow{2}{*}{1.27} & () 70 & $1=0$ & 171 & 158 & 1007 & 101 & 0 & 0 & 05 \\
\hline Meanline & 1.00 & 0.85 & 0.04 & & & 0.10 & 1.50 & 1.71 & 1.50 & $0.9-$ & 1.01 & 0 & 0 & 0.5 \\
\hline Error \% of mean & 0.08 & 0.04 & 0.30 & & & & & & & & & & & \\
\hline
\end{tabular}

Table 14. Optimization based on $\Delta p a y$ and composite desirability function of $\eta$ and $W$ for 3-stage turbine for refined design space (All geometric design variables and output parameters are normalized by the baseline values)

\begin{tabular}{lccc}
\hline & $\eta_{\text {opt }}$ & $\mathrm{W}_{\mathrm{opt}}$ & $\Delta$ pay $_{\mathrm{opt}}$ \\
\hline RSM ( $4 p a y)$ & 1.20 & 1.54 & 0.11 \\
Meanline & 1.21 & 1.54 & 0.11 \\
Error \%of mean & 0.22 & 0.13 & 0.41 \\
\hline RSM $(t=1, s=0)$ & 0.82 & 1.13 & -0.27 \\
Meanline & 0.82 & 1.13 & $-1) .27$ \\
Error \%of mean & 0.04 & 0.02 & 0.31 \\
\hline RSM $(t=0, s=l)$ & 1.24 & 1.75 & 0.09 \\
Meanline & 1.23 & 1.72 & 0.09 \\
Error \%of mean & 1.39 & 1.29 & 1.35 \\
\hline
\end{tabular}

\begin{tabular}{|c|c|c|c|c|c|c|c|c|c|c|c|c|c|c|c|}
\hline & D & $R P M$ & Am. & $\mathbf{h}_{1}$ & $c_{i}$ & on & $c_{y_{3}}$ & $c_{b 1}$ & $c_{b_{2}}$ & $c_{b 3}$ & $\mathbf{s r}_{1}$ & $s_{2}$ & s. & $\mathbf{w f}$ & $\mathbf{w f}_{2}$ \\
\hline $\operatorname{RSM}(\Delta p a y)$ & 1.03 & 1.11 & 0.92 & 1.50 & 1.46 & 0.94 & 0.75 & 0.51 & 0.90 & 0.79 & 0.04 & 0.5 & 0.5 & 0.62 & 0.28 \\
\hline $\operatorname{RSM}(t=l, s=0)$ & 0.50 & 1.27 & 0.70 & 0.96 & 1.71 & 1.76 & 1.41 & 0.73 & 1.41 & 0.17 & 0.5 & 0.5 & 0.5 & 0.4 & 0.3 \\
\hline $\operatorname{RSM}(t=0, s=1)$ & 1.20 & 0.94 & 1.26 & 1.47 & 1.35 & 0.88 & 0.69 & 0.54 & 0.86 & 0.80 & 0 & 0.45 & 0.45 & 0.6 & 0.3 \\
\hline
\end{tabular}


Table 15. Optimization summary for 1,2 and 3-stage turbine with response surface in original design space (All output parameters are normalized by the baseline values)

\begin{tabular}{lllll}
\hline & & $\eta_{\text {opt }}$ & $\mathrm{W}_{\text {opt }}$ & $\Delta$ pay opt \\
\hline \multirow{3}{*}{$\Delta$ pay } & 1-stage & 0.77 & 0.73 & -0.21 \\
& 2-stage & 1.10 & 1.05 & 0.11 \\
& 3-stage & 1.24 & 1.62 & 0.14 \\
\hline \multirow{3}{*}{$(t=1, s=0)$} & 1-stage & 0.40 & 0.41 & -0.61 \\
& 2-stage & 0.65 & 0.66 & -0.34 \\
& 3-stage & 0.85 & 1.13 & -0.23 \\
\hline \multirow{2}{*}{$(t=0, s=1)$} & 1-stage & 0.78 & 0.76 & -0.22 \\
& 2-stage & 1.10 & 1.10 & 0.11 \\
& 3-stage & 1.26 & 1.74 & 0.12 \\
\hline \multirow{2}{*}{$(t=1, s=1)$} & 1-stage & 0.70 & 0.58 & -0.26 \\
& 2-stage & 0.99 & 0.85 & 0.03 \\
& 3-stage & 1.08 & 1.33 & 0.05 \\
\hline
\end{tabular}

Table 16. Optimization summary for 1,2 and 3-stage turbine with response surface in refined design space (All output parameters are normalized by the baseline values)

\begin{tabular}{lllll}
\hline & & $\eta_{\text {opt }}$ & $\mathrm{W}_{\text {opt }}$ & $\Delta$ pay $_{\text {opt }}$ \\
\hline \multirow{2}{*}{$\Delta$ pay } & 1-stage & 0.77 & 0.73 & -0.21 \\
& 2-stage & 1.13 & 1.04 & 0.15 \\
& 3-stage & 1.20 & 1.54 & 0.11 \\
\hline \multirow{3}{*}{$(t=1, s=())$} & 1-stage & 0.40 & 0.41 & -0.61 \\
& 2-stage & 0.65 & 0.65 & -0.35 \\
& 3-stage & 0.82 & 1.13 & -0.27 \\
\hline \multirow{3}{*}{$(t=0, s=1)$} & 1-stage & 0.78 & 0.76 & -0.22 \\
& 2-stage & 1.15 & 1.10 & 0.15 \\
& 3-stage & 1.24 & 1.75 & 0.09 \\
\hline \multirow{2}{*}{$(t=1, s=1)$} & 1-stage & 0.70 & 0.58 & -0.26 \\
& 2-stage & 1.00 & 0.85 & 0.04 \\
\hline
\end{tabular}

Table 17.The quality of the Second-Order Response Surface obtained for $\eta$. $W$ and $\Delta p a y$ of 2-Stage Turbine for 1990-data (FCCD criterion) and 249-data (OA criterion)

(Mean values of $\eta$. $W$ and $\Delta p a y$ are normalized by the baseline values)

\begin{tabular}{llccc}
\hline & & $\eta$ & $W$ & spay \\
\hline \multirow{4}{*}{ 1990-data } & $\mathrm{R}^{2}$ & 0.995 & 0.996 & 0.995 \\
& $\mathrm{Ra}^{2}$ & 0.994 & 0.996 & 0.995 \\
& ims- error & $1.31 \%$ & $2.56 \%$ & $9.58 \%$ \\
& Mean & 0.78 & 0.86 & -0.24 \\
\hline \multirow{4}{*}{ 249-data } & $\mathrm{R}^{2}$ & 0.995 & 0.998 & 0.994 \\
& $\mathrm{Ra}^{2}$ & 0.992 & 0.997 & 0.992 \\
& $m m s$ - error & $2.128 \%$ & $0.826 \%)$ & $20.68 \%$ \\
& Mean & 0.89 & 0.92 & -0.11 \\
\hline
\end{tabular}


Table 18. Testing of the Second-Order Response Surface obtained for $\eta$ and $W$ of 2-Stage Turbine for 1990-data (FCCD criterion) and 249-data (OA criterion) with 78- test data

\begin{tabular}{|c|c|c|c|}
\hline \# of design points & \# of test data & rms-error for $\eta(\%)$ & rms-error for $\mathrm{W}(\%)$ \\
\hline 249 & 78 & 1.65 & 0.96 \\
\hline 1990 & 78 & 1.67 & 1.21 \\
\hline
\end{tabular}

Table 19. Optimization based on $\Delta$ pay and composite desirability function of $\eta$ and $W$ for 2 -stage turbine for original design space with 249-data (OA criterion). (All geometric design variables and output parameters are normalized by the baseline values)

\begin{tabular}{|c|c|c|c|c|c|c|c|c|c|c|c|c|c|c|}
\hline & $\eta_{\text {opt }}$ & $\mathbf{W}_{\text {opt }}$ & $\Delta$ pay $_{\text {opt }}$ & $\mathrm{D}$ & $R P M$ & $A_{\text {ann }}$ & $h_{1}$ & $\mathrm{c}_{\mathrm{v} 1}$ & $c_{v 2}$ & $c_{b 1}$ & $c_{b 2}$ & $\mathbf{s r}_{1}$ & $\mathrm{sr}_{2}$ & $w_{f 1}$ \\
\hline \begin{tabular}{|l|} 
RSM $(\Delta p a y)$ \\
Meanline
\end{tabular} & 1.13 & 1.04 & $\frac{0.15}{0.14}$ & 1.13 & 1.02 & 1.10 & 1.50 & 1.71 & 0.44 & 0.92 & 0.62 & 0.0 & 0.4 & 0.9 \\
\hline \begin{tabular}{|l|} 
Meanline \\
Error \%of mean \\
\end{tabular} & $\frac{1.12}{1.73}$ & $\frac{1.03}{1.39}$ & $\begin{array}{l}0.14 \\
5.90 \\
\end{array}$ & & & & & & & & & & & \\
\hline \begin{tabular}{|l|}
$\mathbf{R S M}(t=1, s=0)$ \\
Meanline \\
\end{tabular} & $\begin{array}{l}0.64 \\
0.62 \\
\end{array}$ & $\begin{array}{l}0.64 \\
0.64\end{array}$ & $\begin{array}{l}-0.36 \\
-0.38 \\
\end{array}$ & 0.50 & 1.27 & 0.70 & 0.90 & 0.39 & 0.26 & 0.92 & 1.13 & 0.5 & 0.5 & 0.5 \\
\hline Error \% of mean & 1.85 & 0.62 & 7.15 & & & & & & & & & & & \\
\hline $\operatorname{RSM}(t=0, s=1)$ & 1.13 & 1.09 & 0.14 & \multirow{2}{*}{1.21} & \multirow{2}{*}{0.95} & \multirow{2}{*}{1.27} & \multirow{2}{*}{1.50} & \multirow{2}{*}{1.71} & \multirow{2}{*}{0.53} & \multirow{2}{*}{0.85} & \multirow[t]{2}{*}{0.68} & \multirow{2}{*}{0.0} & \multirow[t]{2}{*}{0.3} & \multirow[t]{2}{*}{0.9} \\
\hline Meanline & 1.13 & 1.09 & 0.14 & & & & & & & & & & & \\
\hline Error \% of mean & 0.90 & 1.02 & 2.76 & & & & & & & & & & & \\
\hline $\operatorname{RSM}(t=1, s=1)$ & 0.99 & 0.82 & 0.03 & \multirow{2}{*}{0.91} & \multirow{2}{*}{1.27} & \multirow{2}{*}{0.70} & 0.90 & 0.39 & 1.76 & 0.21 & 1.13 & 0.5 & 0.0 & 0.9 \\
\hline Meanline & 0.96 & 0.83 & 0.00 & & & & & & & & & & & \\
\hline Error $\%$ of mean & 2.67 & 0.49 & 11.88 & & & & & & & & & & & \\
\hline
\end{tabular}

Table 20. Optimization based on $\Delta$ pay and composite desirability function of $\eta$ and $W$ for 2-stage turbine for refined design space for 249 -data (OA criterion). (All geometric design variables and output parameters are normalized by the baseline values)

\begin{tabular}{|c|c|c|c|c|c|c|c|c|c|c|c|c|c|c|}
\hline & $\eta_{\text {opt }}$ & $W_{o p t}$ & $\Delta$ pay $_{\text {opt }}$ & $\mathrm{D}$ & $R P M$ & $A_{\mathrm{ann}}$ & $\mathrm{h}_{1}$ & $c_{\mathrm{v} 1}$ & $c_{\mathrm{v} 2}$ & $c_{b 1}$ & $c_{b 2}$ & $\mathrm{Sr}_{1}$ & $\mathrm{sr}_{2}$ & $w_{f 1}$ \\
\hline RSM ( $1 p a v)$ & 1.13 & 1.02 & 0.16 & \multirow{2}{*}{1.10} & \multirow{2}{*}{1.05} & \multirow{2}{*}{1.03} & \multirow{2}{*}{1.50} & \multirow{2}{*}{1.57} & \multirow{2}{*}{0.53} & \multirow{2}{*}{0.85} & \multirow{2}{*}{0.51} & \multirow{2}{*}{0.1} & \multirow{2}{*}{0.3} & \multirow{2}{*}{0.9} \\
\hline Meanline & 1.12 & 1.02 & 0.15 & & & & & & & & & & & \\
\hline Error $\%$ of mean & 0.04 & 0.01 & 0.37 & & & & & & & & & & & \\
\hline $\mathbf{R S M}(t=1, s=0)$ & 0.62 & 0.64 & -0.38 & \multirow{2}{*}{0.50} & \multirow{2}{*}{1.27} & \multirow{2}{*}{0.70} & \multirow{2}{*}{0.90} & \multirow{2}{*}{0.39} & \multirow{2}{*}{0.26} & \multirow{2}{*}{0.92} & \multirow{2}{*}{1.13} & \multirow{2}{*}{0.5} & \multirow{2}{*}{0.5} & \multirow{2}{*}{0.5} \\
\hline Meanline & 0.63 & 0.64 & -0.38 & & & & & & & & & & & \\
\hline Error \%of mean & 0.0031 & 0.0002 & 0.0002 & & & & & & & & & & & \\
\hline $\operatorname{RSM}(t=0, s=1)$ & 1.13 & 1.10 & 0.15 & \multirow{2}{*}{1.23} & \multirow{2}{*}{0.93} & \multirow{2}{*}{1.30} & \multirow{2}{*}{1.50} & \multirow{2}{*}{1.57} & \multirow{2}{*}{0.70} & \multirow{2}{*}{0.78} & \multirow{2}{*}{0.62} & \multirow{2}{*}{0.1} & \multirow{2}{*}{0.2} & \multirow{2}{*}{0.9} \\
\hline Meanline & 1.14 & 1.10 & 0.15 & & & & & & & & & & & \\
\hline Error \%of mean & 0.005 & 0.001 & 0.029 & & & & & & & & & & & \\
\hline $\operatorname{RSM}(t=l, s=1)$ & 0.97 & 0.84 & 0.02 & \multirow{2}{*}{0.90} & \multirow{2}{*}{1.27} & 0.70 & 090 & 039 & 176 & 028 & 113 & 0.5 & 0.0 & 08 \\
\hline Meanline & 0.98 & 0.84 & 0.02 & & & 0.10 & & 0.07 & 1.70 & & & & & \\
\hline Error \%of mean & 0.08 & 0.05 & 6.08 & & & & & & & & & & & \\
\hline
\end{tabular}




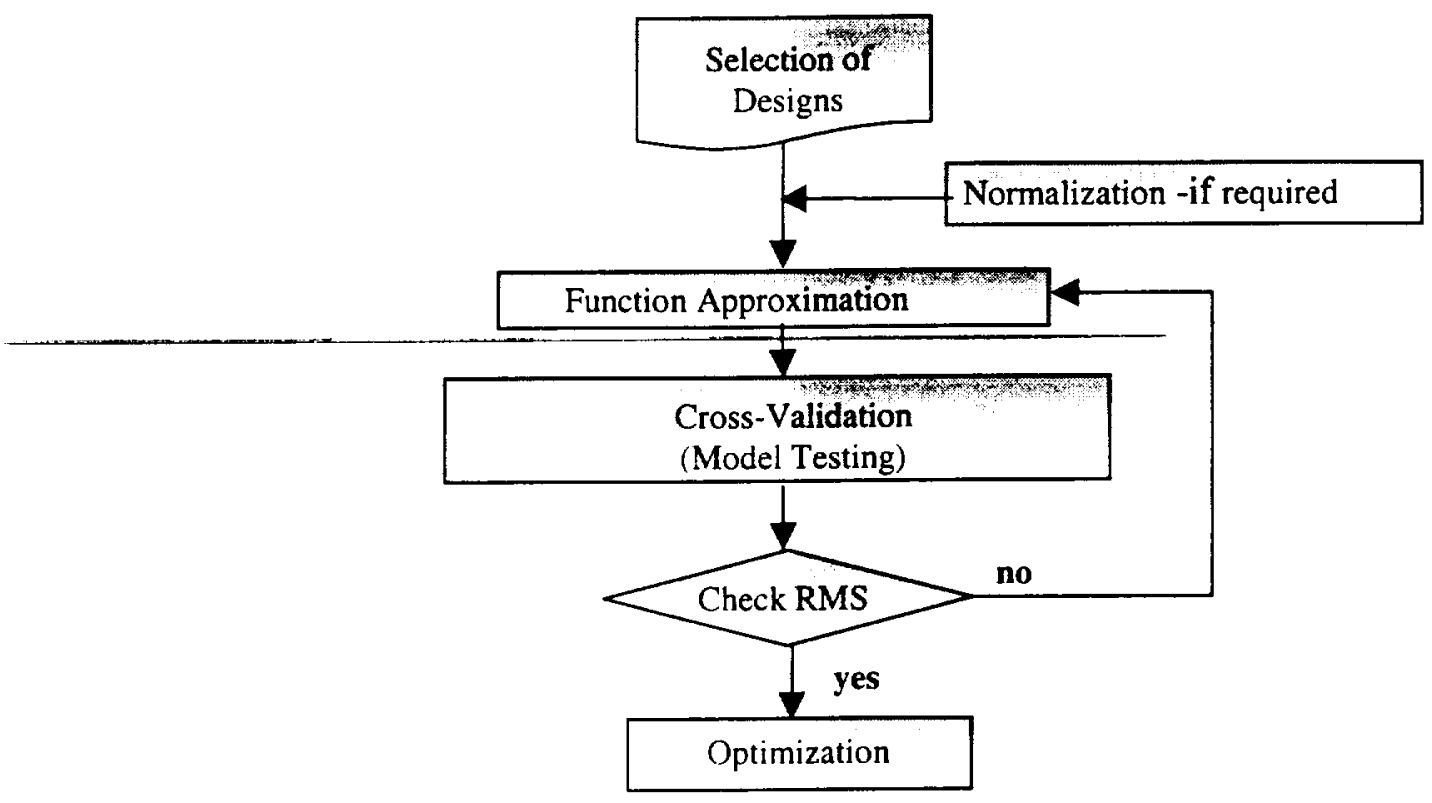

Figure 1. Function Approximation and Optimization Flow Chart

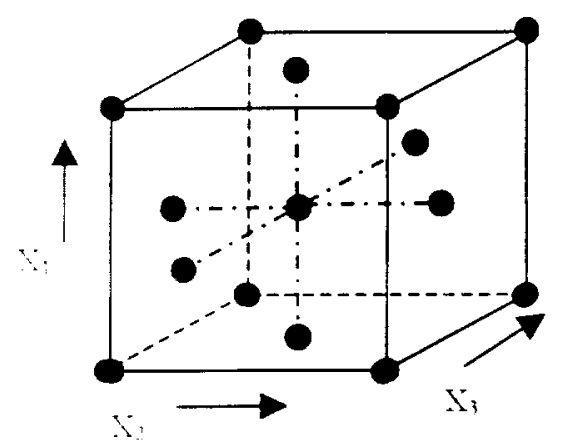

Figure 2. Face (entered Composite Designs (FCCD) for 3 Design Variables

15

American Institute of Aeronautics and Astronautics 


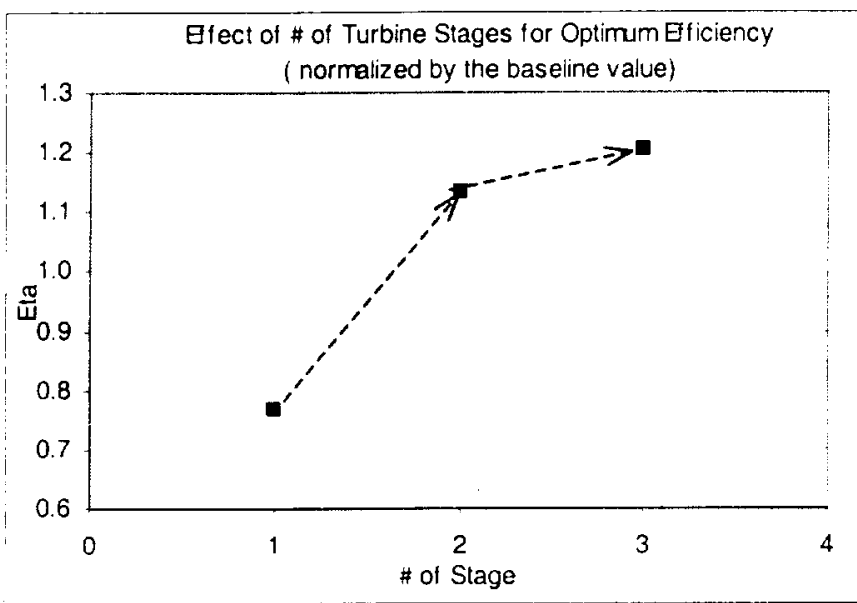

Ef ect of \# of Turbine Stagesfor Optimum Weight

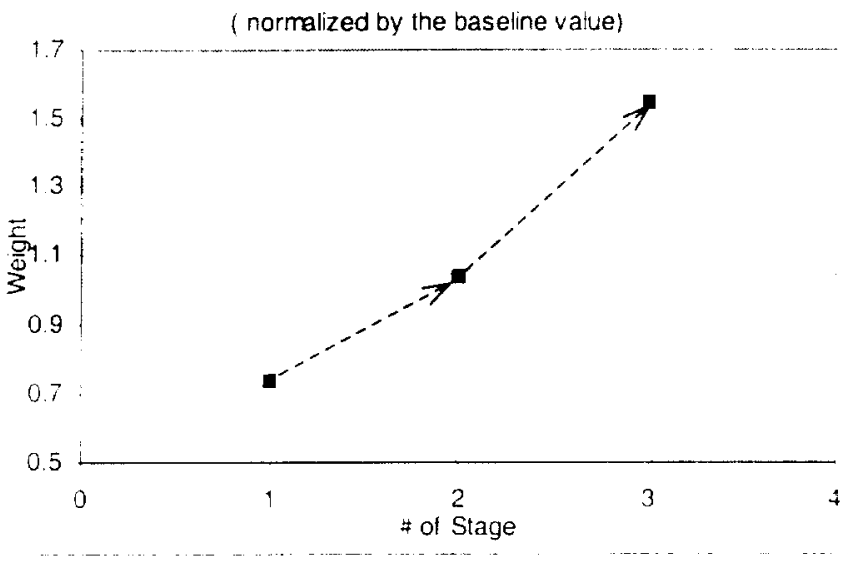

Elfect of $\#$ of Turbine Stages for Optimum ncremental Payload Change ( normalized by the baseline value)

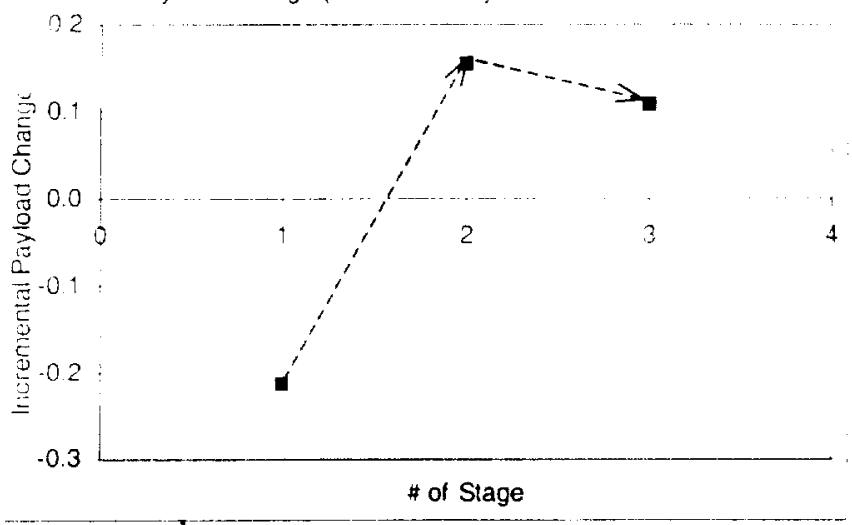

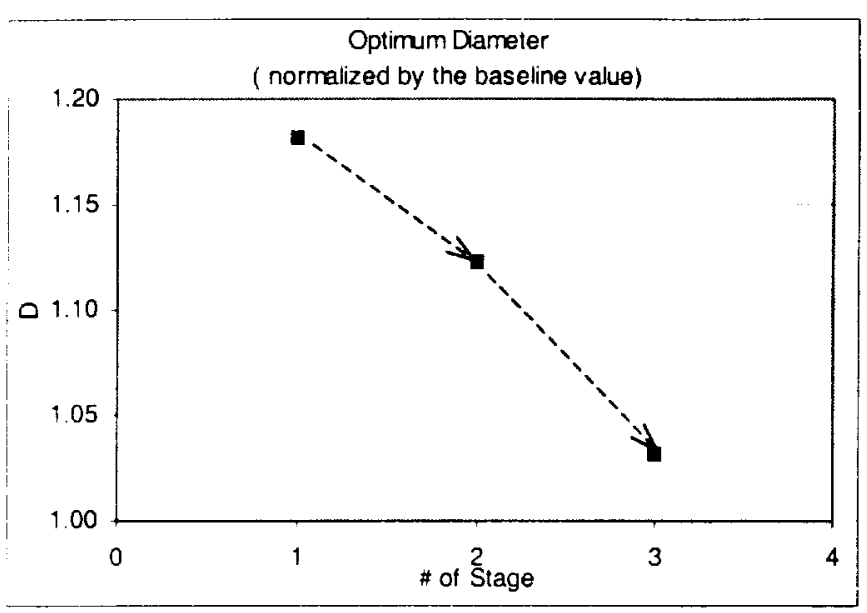
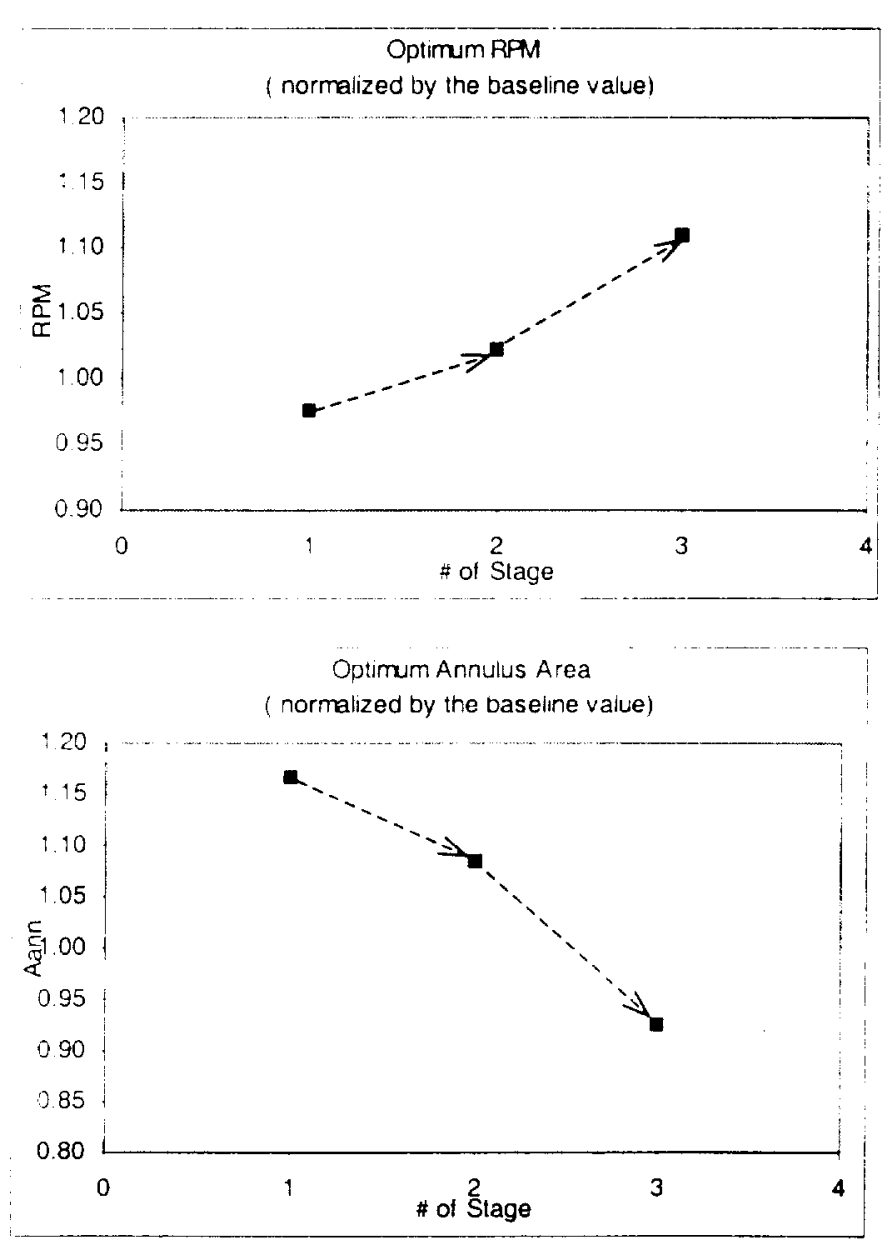

Figure 3. Effect of the number of turbine stage on optimum design parameters; $D$, RPM, and $A$ mind optimum output parameters: $\eta$. W. and $\Delta p a y$ calculated for $\Delta p a y$-based optimization

(All geometric design variables and output parameters are normalized by the baseline values) 

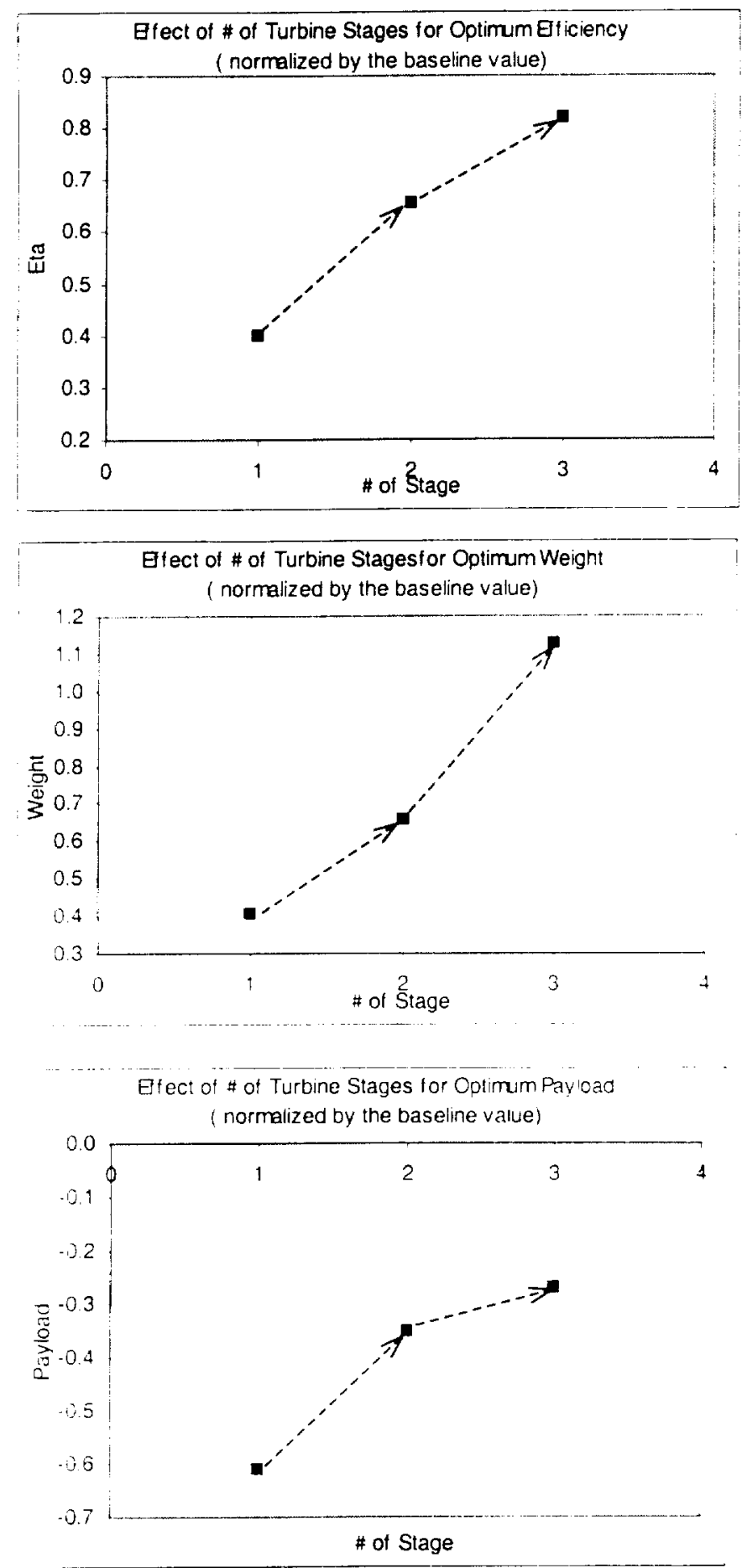
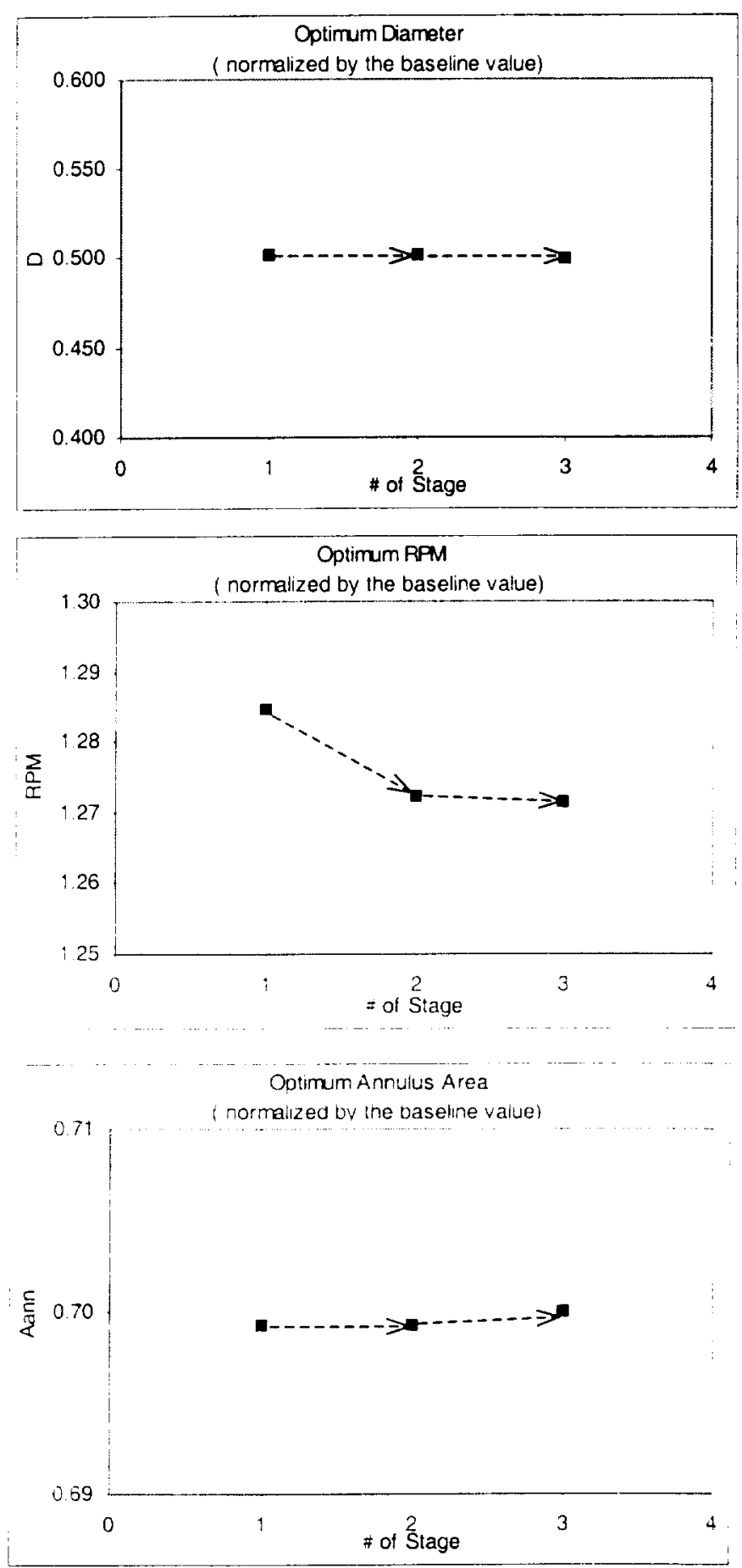

Figure 4. Effect of the number of turbine stage on optimum design parameters; $D, R P M$, and $A_{t a n}$ and optimum output parameters: $\eta, W$, and $\Delta p a y$ calculated for Weight-based optimization $(t=l, s=())$

(All geometric design varrables and output parameters are normalized by the baseline values) 

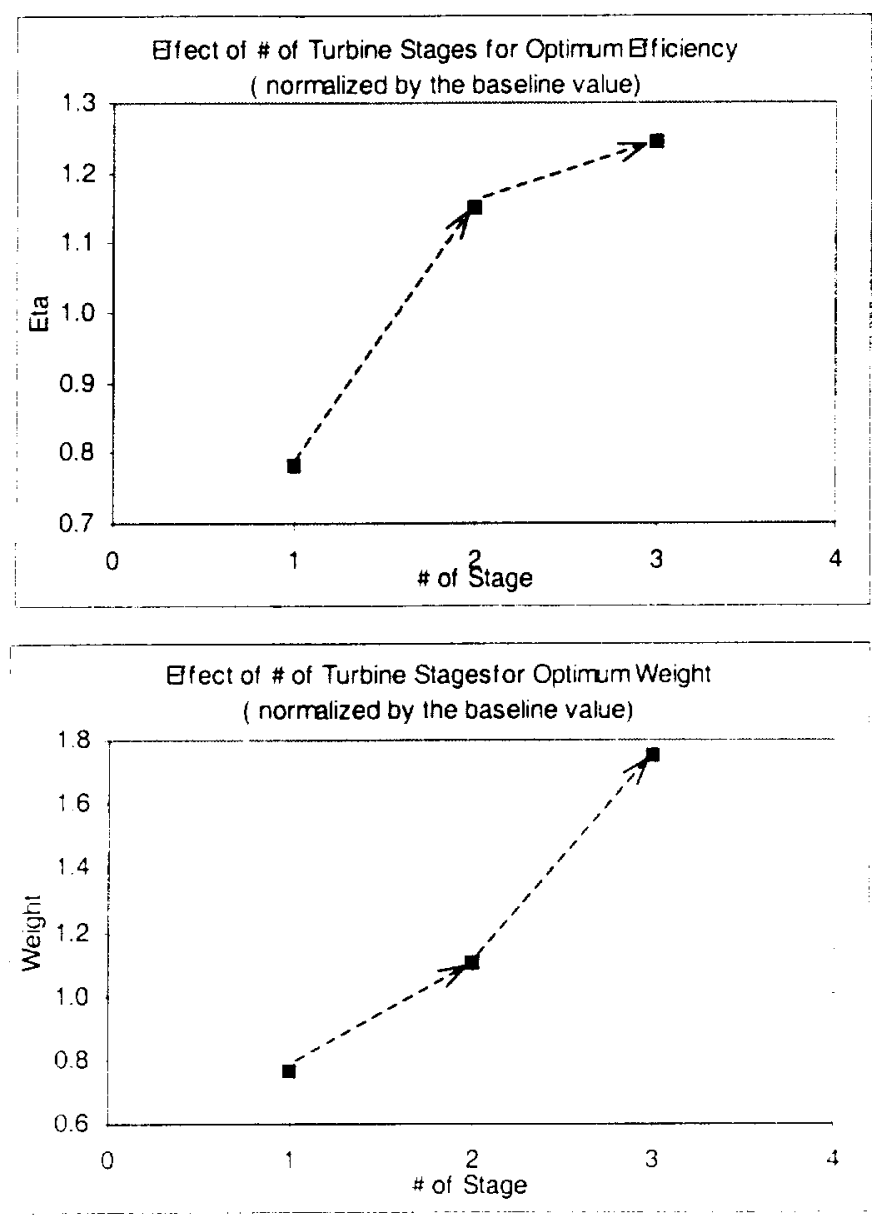

Elect of \# of Turbine Stages for Optimum Payioad

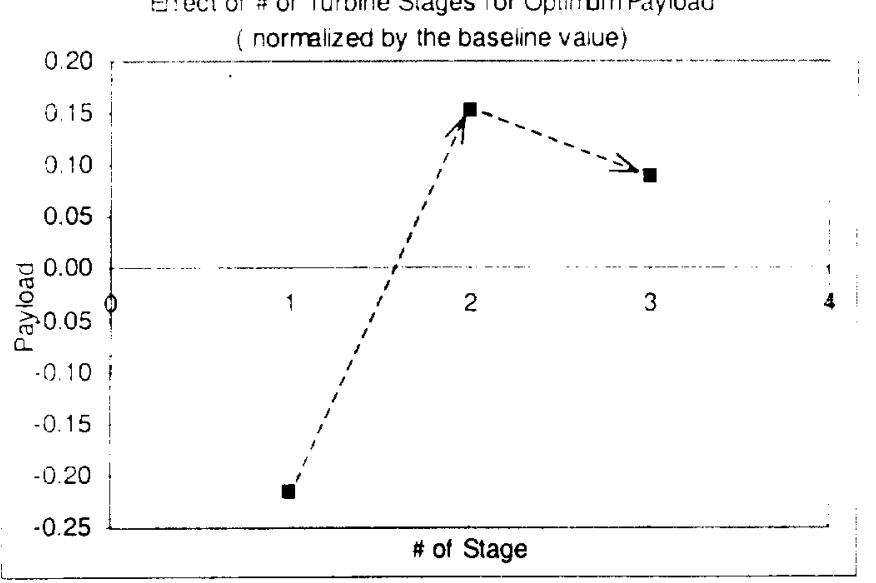

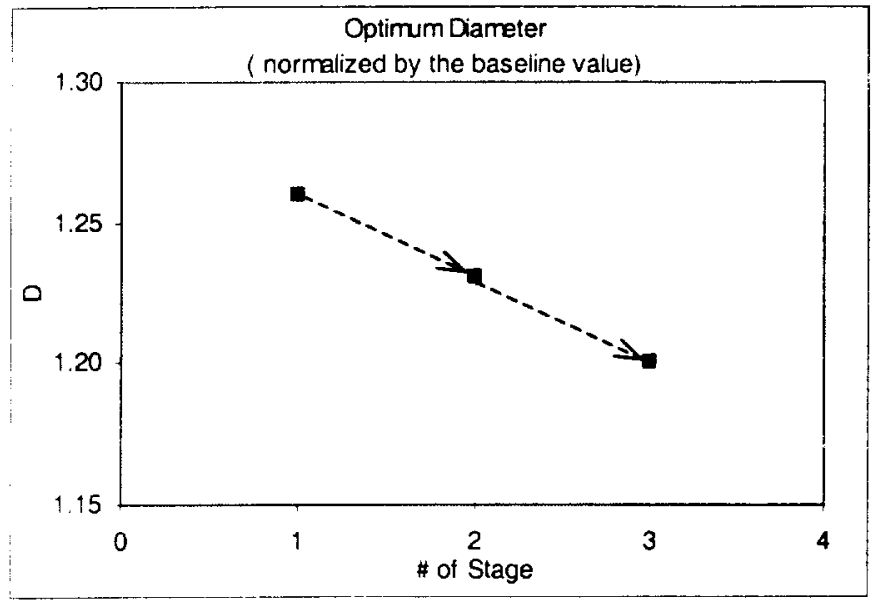
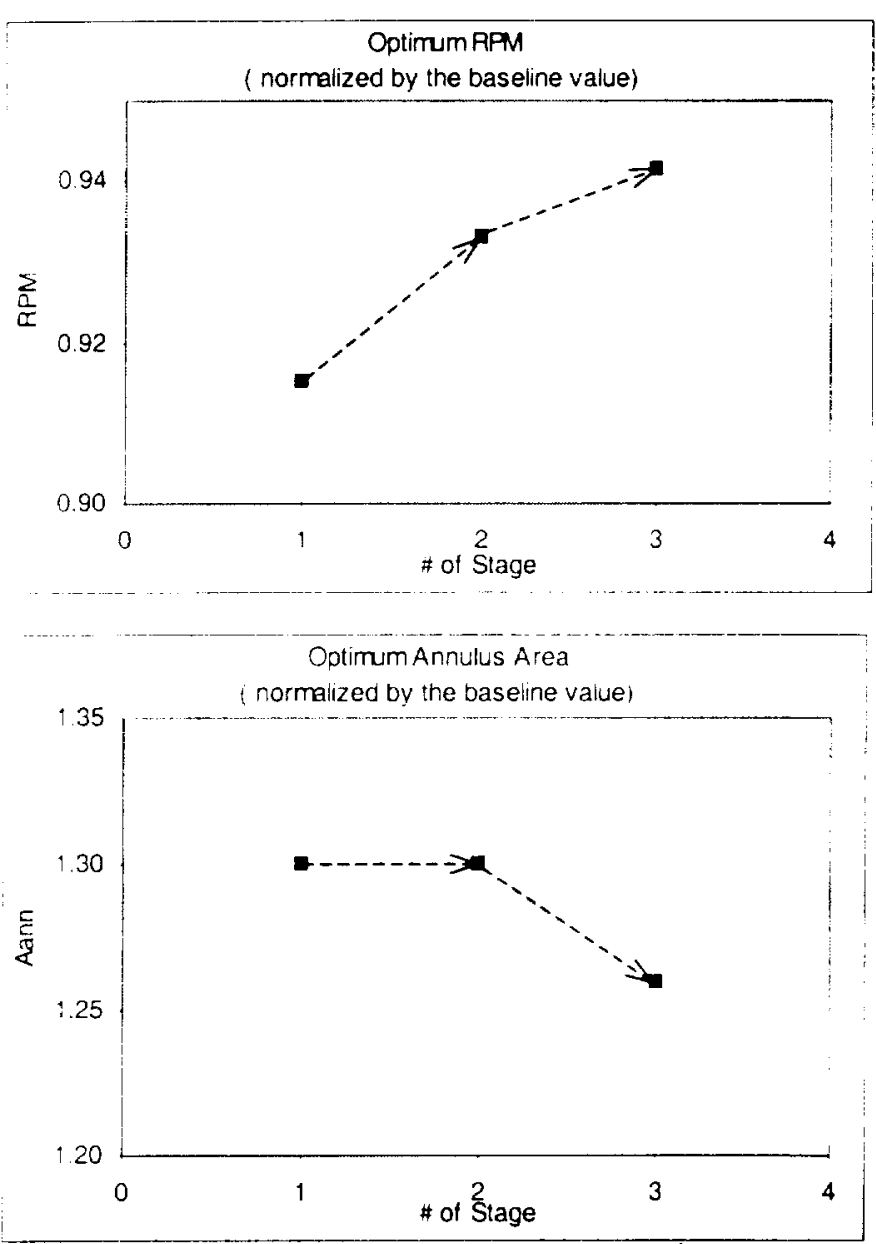

Figure 5. Effect of the number of turbine stage on optimum design parameters; $D, R P M$, and $A_{t a m}$ and optimum output parameters; $\eta, W$. and spay calculated

for $\eta$-based optimization $(t=0, s=1)$

(All geometric design variables and output parameters are normalized by the baseline values) 
$\alpha$-plot for $\Delta$ pay Response Surface for 2-Stage Turbine (normalized by the baseline value )

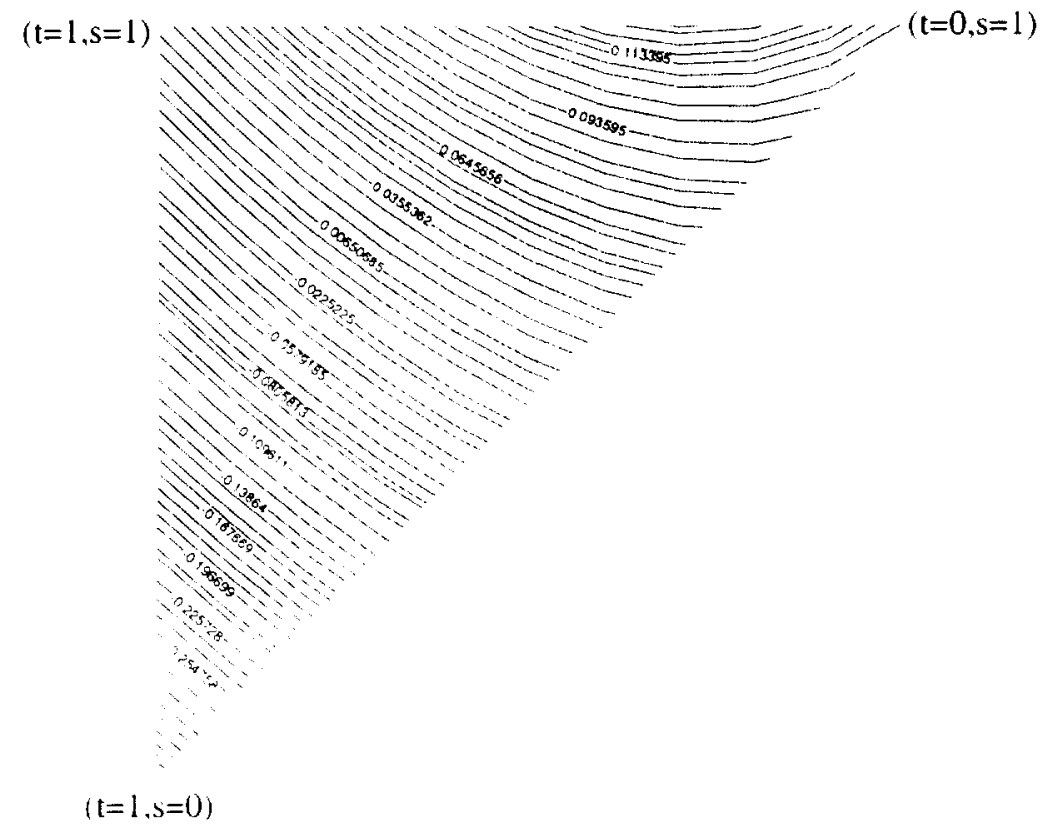

$(t=1, s=1)$
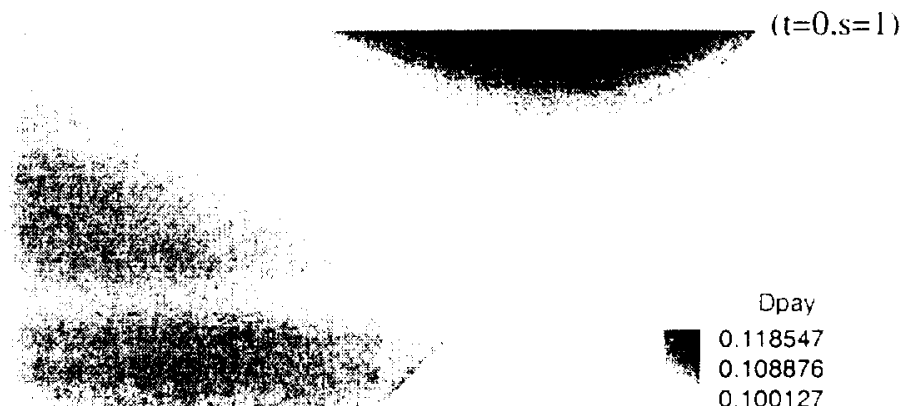

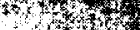
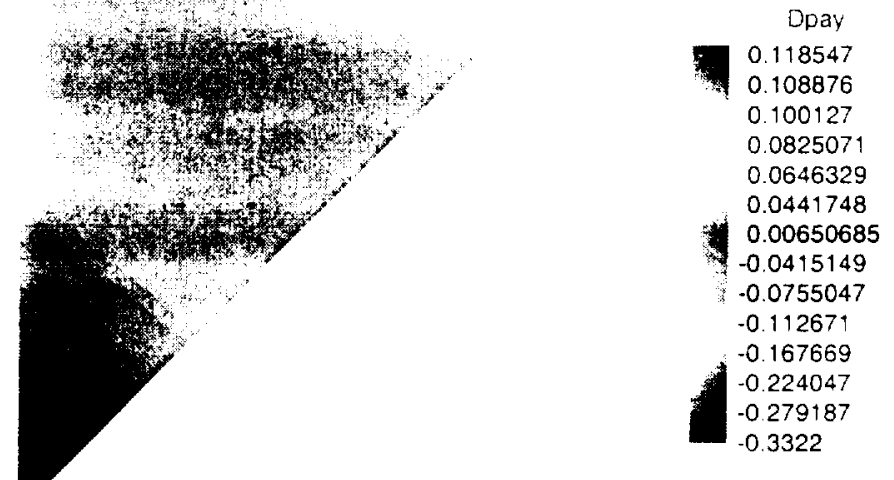

$(\mathrm{t}=1, \mathrm{~s}=0)$

Figure 6. $\alpha$-Plot tor $A p a y$ (normalized by the baseline values ) Response Surface for 2-Stage Turbine based on composite desirability function optimization (Effect of values of $t$ and $s$ on optimum $\Delta p a y$ ) 


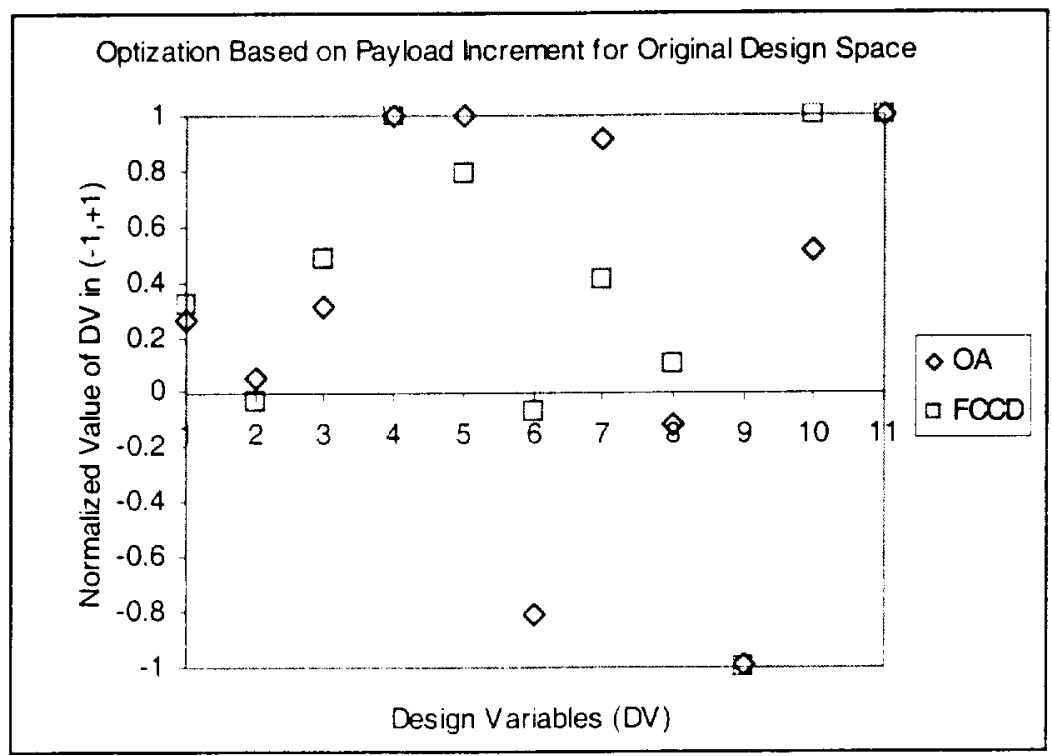

(a) Original Design Space

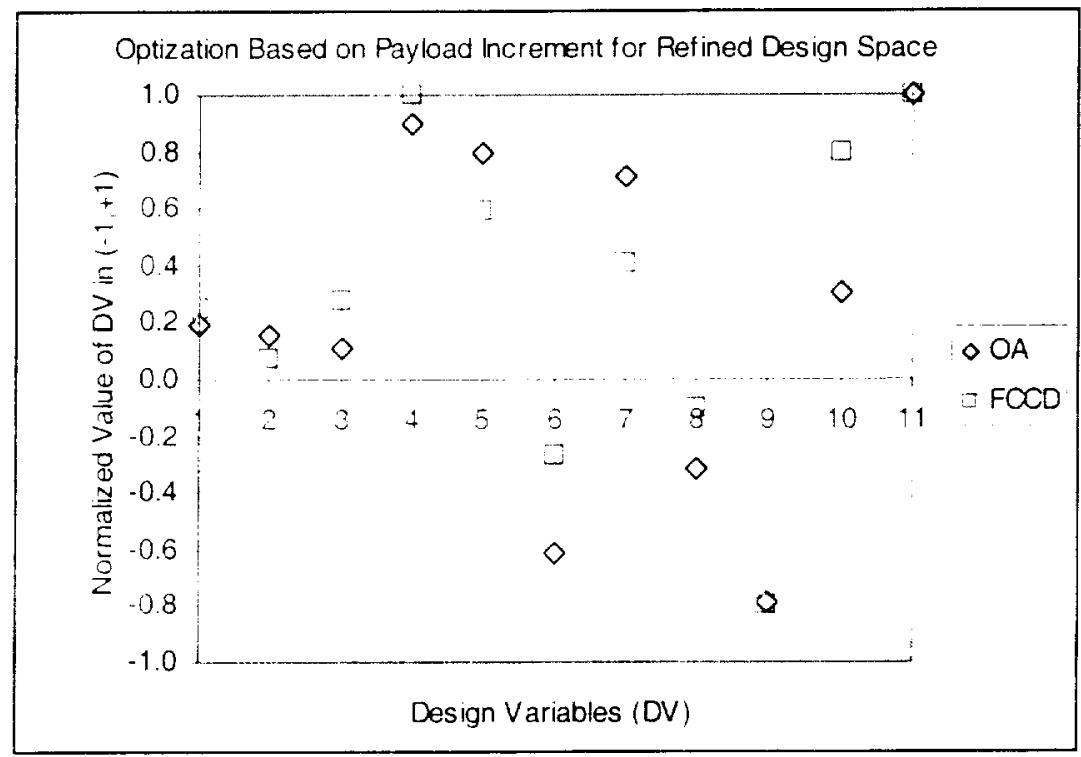

(b) Refined Design Space

Figure 7. Comparison of the Design Variables for Optimization based on Payload Increment (Jpay) using 1990 data (FCCD) and 249-data (OA) tor both Original Design Space and Retined Design Space

(DV\#1: D, DV\#2:RPM, DV\#3: $A_{a n n}$, DV\#4: $h_{1}$, DV\#5: $c_{v 1}, D V \# 6: c_{v 2}, D V \# 7: c_{b 1}, D V \# 8: c_{b 2}, D V \# 9: s_{1}, D V \# 10:$ $s r_{2}$, and DV\#11: $w_{\mathrm{fl}}$ ) 